\title{
Louis-Joseph Proust y los primeros análisis de carbones asturianos. Crónica de unos ensayos químicos olvidados en la historia minero-industrial de Asturias
}

\author{
Luis Aurelio González Prieto(1), Pelayo González-Pumariega Solís ${ }^{(2)}$ y David González Palomares ${ }^{(3)}$ \\ (1) Instituto de Educación Secundaria Rey Pelayo, Avenida Constantino González s/n, 33550 Cangas de Onís (Asturias). \\ laureliogp@gmail.com \\ (2) Escuela Politécnica de Mieres, Universidad de Oviedo, Gonzalo Gutiérrez s/n, 33600 Mieres (Asturias). \\ pelayogs@uniovi.es \\ (3) Facultad de Filosofía y Letras, Universidad de Oviedo, Amparo Pedregal s/n, 33011 Oviedo. \\ davidgpalomares@gmail.com
}

\section{RESUMEN}

La historiografía minera ha considerado que los primeros ensayos químicos de los carbones asturianos fueron realizados a comienzos de los años cuarenta del siglo XIX por el químico inglés John Thomas Cooper y el ingeniero francés Adrien Paillette, siendo de escasa calidad científica y fruto de la urgencia de los intereses económicos y empresariales del momento. Por su parte, Jovellanos refirió que tras la creación de la Real Fábrica de municiones deTrubia, Louis-Joseph Proust había participado en los ensayos realizados en sus hornos de fundición, sin que posteriormente se haya investigado más sobre este asunto. Tan solo en 1986 Luis Adaro Ruíz-Falcó publicó un documento que refiere el envío de carbones de Langreo al laboratorio de la Escuela de Artillería de Segovia para que fuesen analizados por Proust y estudiase la posibilidad de utilizarlos como combustible para obtener hierro de calidad en los hornos de Trubia, aunque se lamentaba de no haber localizado los resultados de los mismos. La reciente digitalización de gran número de publicaciones y revistas científicas de finales del siglo XVIII y del XIX ha permitido la localización de dos escritos de Proust que permanecían completamente olvidados. En uno de ellos describe con detalle los distintos carbones asturianos analizados, así como los resultados obtenidos, y los compara con otros de procedencia inglesa y de varios puntos de España. Consideramos que dar a conocer estos importantes documentos e integrarlos en el contexto de la época constituye una aportación significativa a la historia minero-industrial de Asturias.

Palabras clave: Análisis geoquímico, carbón, coque, historia minero-industrial de Asturias, Louis-Joseph Proust.

\section{Louis-Joseph Proust and the first analysis of Asturian coal. Chronicle of some forgotten chemical tests in the mining-industrial history of Asturias}

\begin{abstract}
Mining historiography has considered that the first chemical tests of Asturian coal were carried out in the early 1840 s by the English chemist Thomas Cooper and the French engineer Adrien Paillette, and were of low scientific quality and the result of the urgency of the economic and business interests of the moment. For his part, Jovellanos reported that after the creation of the Trubia Munitions Factory, Louis-Joseph Proust had participated in the tests carried out in his smelting furnaces, without further investigation on this matter. It was not until 1986 that Luis Adaro Ruíz-Falcó published a document that refers the shipment of Langreo coal to the laboratory of the Artillery School of Segovia, to be analyzed by Proust and to study the possibility of using them as fuel to obtain quality iron in the Trubia furnaces, although he regretted not having located the results of the same. The digitization of a large number of scientific publications and magazines from the late eighteenth and nineteenth centuries, has allowed us to find two completely forgotten texts of Proust in which he describes the different Asturian coal analyzed, as well as the results obtained, comparing them with others of English origin and from various parts of Spain (Bélmez, Extremadura and Villanueva del Río). We consider that making these important documents known and integrating them in the context of the time period in which they were produced, constitutes a significant contribution to the industrial-mining history of Asturias.
\end{abstract}

Keywords: coal, coke, geochemical analysis, Louis-Joseph Proust, industrial-mining history of Asturias. 


\section{ABRIDGED ENGLISH VERSION}

\section{ABRIDGED ENGLISH VERSION}

\section{Introduction}

Louis Joseph Proust (Angers, 1754-1826) (Figure 1) is considered one of the fathers of modern chemistry for having proposed the Law of Definite Proportions, which also receives his name. Although his life history is well known, his tests with coal to establish their comparative combustibility for use in metallurgical foundry have gone unnoticed.

\section{The work carried out by Proust in Spain}

Proust developed most of his professional career in Spain: first a brief stay in 1779 in the chair of chemistry at the Real Seminario Patriótico Bascongado (Vergara, Guipúzcoa); from 1794 on he was appointed Professor of Chemistry at the Real Colegio de Artillería de Segovia and, finally, in 1798 Director of the Real Escuela Práctica de Química in Madrid.

He was also in charge of spreading the knowledge acquired through his experiments, creating the Anales del Real Laboratorio de Química de Segovia and contributing to Anales de Historia Natural, as well as studying various scientific-technical aspects of Spanish industries.

\section{The analysis of coal and the smelting of iron in Proust's time}

In the seventeenth century, the accelerated deterioration of the forests made it necessary to look for viable alternatives to charcoal. Coke was invented entirely empirically and turned out to be an optimal product for melting iron in blast furnaces.

The great variety of coal that existed made their chemical analysis become an essential tool to know the advantages that each one was able to offer and to be able to use the most suitable one for the proposed purposes. Until well into the 19th century, several scientists, such as Morand, Kirwan or Fabbroni, warned that the analysis of stone charcoal presented many singularities and great difficulties. Spain was behind in these matters, and the naval engineer Casado de Torres was the first national scientist to carry out coal analysis.

On the other hand, the manufacture of metallurgical coke also involved a certain complexity, as pointed out by Jars, Gazeran or Bonnard, and chemists were still unaware of the role that coal really played in the iron ore smelting process.

\section{Coal in Proust's written work}

In 1798 Proust carried out a series of chemical analyses with vegetable and mineral coals to try to solve the problems that arose when smelting iron with coke in the recently created arms and ammunition factories in Oviedo and Trubia (Asturias). The following year he published a preview of his research in the Journal de Physique, Chimie, d'Histoire Naturelle et des Arts (JPCHNA) with the title Sur la proportion du charbon dans quelques bois, et sur celle des charbons de terre, in which he indicated that pit-coal was much more advantageous as a fuel than any other known wood, since it left three times the carbonaceous matter and less ash, taking as an example the coal of Asturias, Villanueva (Sevilla) and Bélmez (Córdoba).

In 1806 he published in this same journal the extensive memoir Faits pour servir à l'Histoire des charbons de terre (Figure 2). He begins by providing a list of the results he had obtained with nine Spanish types of pit-coal and one English type. Seven of them came from Asturian mines in the municipalities of Langreo, Siero, Riosa and Quirós (Table 1). Proust points out that, in general, Asturian coal was presented in thin veins, embedded between thin layers of clay, with a highly variable arrangement, and that its pyrite content spoiled the quality of the coal. These drawbacks led him to conclude that it would not be possible to establish foundries in Asturias such as those in England or those in Mont-Cenis, as it was not possible to obtain enough coal to power such large furnaces on a daily basis. 
Next, he includes a comparative table with the results of the analyses of the different types of coal (Table 2), the proportion between the aqueous product and the oil obtained after distillation (Table 3) and the amounts of coke and oil (Table 4). Finally, he highlights the characteristics that he was able to verify in types of Spanish coal, noting that the coke they contributed ranged between 60 and $80 \%$. However, he also noted that the coal richest in bitumen was not the easiest to distill by the method devised by Lord Dundonald. This appreciation is very important in order to understand the problems encountered by Asturian smelters, since the Langrean coal was by far the richest in bitumen.

Between 1810 and 1813 the JPCHNA published another lengthy article by Proust in nine installments entitled Faits pour servir a l'étude de la poudre à canon. It is especially striking that, despite his extensive experience in the analysis of mineral coal, he did not even attempt to prove its possible usefulness for the preparation of the deflagrating mixture.

\section{Proust's intervention in the arms factory of Oviedo and ammunition factory in Trubia (Asturias)}

In 1794 the Spanish government ordered the construction of an ammunition factory in Trubia and another for portable weapons in Oviedo (Asturias), with the intention that the coal from the Langreo mines would be used in both of them, as was already being done in the most advanced countries of Europe. However, as the tests carried out in Oviedo had not been successful, in 1796 Proust was asked to give his opinion on the matter, for which he carried out the analysis of the coal used. Finally in 1798, after convincing the Guipuzcoan Guild of Bayonetists of the superior quality of pitcoal, the barrels of rifles and pistols were forged in the forges.

Problems also arose when trying to melt iron with coke in the blast furnaces built in Trubia, but in this case, neither Proust's advice nor the practice acquired by the artillery captain Francisco Dátoli in the Le Creuzot foundry could solve them, so the charcoal had again to be used. Proust attributed this setback to the design defects of the furnaces, although Jovellanos indicated, more correctly, that it was unknown if the bad result was due to the size or shape of the furnaces, the quantity or quality of the veins, the essence or preparation of the coal, the tubes or blowing engines, the mixtures or fluxes, or the method of the operation itself.

\section{The repercussion in the European scientific context of the analyzes of the pit-coal carried out by Proust}

In 1807 Proust's essays about pit-coal were already cited by Delamétherie and Brongniart, but they would reach a wide circulation after their publication in German by the Journal für die Chemie und Physik, and in English by the Journal of Natural Philosophy, Chemistry and the Arts and The Repertory of Arts, Manufactures and Agriculture (Figure 3).

Thus, references would frequently appear in chemistry books such as Chemisches Wörterbuch, by Klaproth and Wolf (1808); Léçons de géologie, by Delamétherie (1816) and Dictionary of Chemistry, by Ure (1821); as well as in some of the most important compendia of metallurgy, such as La Sidérotechnie, by Hassenfratz (1812); Handbuch der Eisenhüttenkunde, by Karsten (1816), and L'art du maître de forges, by Pelouze (1828). These references are still maintained in some books and scientific articles after the middle of the 19th century. Such is the case of the prestigious Encyclopaedia Britannica, in the entry of the term charcoal (1854), or the article by B.H. Paul entitled On Destructive Destillation, published in 1863 in The Journal of the Society of Arts, The Chemical News and Journal of Physical Science and The Engineer.

\section{The complete absence of references to Proust in the studies and analysis of Asturian coal carried out in the 19th century}

Despite the notable diffusion that Proust's analyses had on the European continent, his results were not cited by the technicians who studied and made known the Asturian mining basins between 1830 and 1860.

The first absences are found in the report on the coal mines of the province of Asturias published in 1831 by Ezquerra, Bauzá, Amar and García, and in the article Note géologique sur les Asturies de Buvignier (1839). More surprising is the lack of knowledge of Proust's work shown by the English chemist John Thomas Cooper and the French engineer Adrien Paillette, since they were the ones who carried out new analyses of Asturian coal at the beginning of the 1840s, at the time when an attempt was being made to reinforce the creation of iron and steel 
industries in the region. And, above all, by Artillery Captain Manuel de Azpiroz who analysed the coal from the main deposits in the region in the laboratory of the Trubia Factory in the early 1850s. For his part, the mining engineer Guillermo Schulz, who was the one who best studied the geology of the region at that time, only referred to the docimastic tests made by Paillette and Azpiroz.

From then on, the omission of the analytical work carried out by Proust became general in all the studies that appeared on the history of Asturian coal. Only the researcher Luis Adaro Ruiz-Falcó noticed the prestigious French chemist's tests, although he deeply regretted not being able to locate their results.

\section{Conclusions}

In 1804 José Vicente Pereda wrote a Memoria sobre el carbón fósil commissioned by the Junta General del Principado de Asturias, in which he stated that Proust was responsible for the government's decision to abandon the exploitation of the coal mines. Therefore, his chemical analyses had had a transcendental impact on the mining-industrial history of Asturias.

In addition, the efforts made by the State to reconvert the traditional smelting process to one based on mineral coal failed. Although the lack of experience in the preparation and handling of coke had a decisive influence, this question, like the chemical analyses of mineral coal carried out by Proust, has not been considered by the mining-industrial historiography of Asturias and deserves an in-depth study.

\section{Introducción}

En la historiografía de la minería asturiana siempre se ha mantenido que los primeros ensayos químicos de los carbones extraídos en la región fueron realizados a principios de la década de los cuarenta del siglo XIX por el químico inglés John Thomas Cooper (17901854 ) y por el ingeniero francés Adrien Paillette (18091858). Además, se consideró que estos análisis habían tenido escasa calidad científica y que fueron fruto de la urgencia de los intereses económicos y empresariales del momento (Peret et al., 1978).

Sin embargo, Gaspar Melchor de Jovellanos (17441811) dejó escrito en sus Diarios (Jovellanos, 1797) que tras la creación de la Real Fábrica de municiones gruesas de Trubia, Louis-Joseph Proust (1754-1826), encargado en aquel momento de la cátedra de química de la Escuela de Artillería de Segovia, había tomado parte activamente en los ensayos realizados en los dos hornos de fundición de hierro establecidos en aquella instalación que, por diferentes causas, no habían conseguido obtener las coladas adecuadas. Curiosamente, con posterioridad no ha habido más aportaciones significativas sobre esta actividad del prestigioso químico francés.

La única referencia al asunto que nos ocupa data de los años noventa del siglo XX, cuando el gran historiador de la industria minero-siderúrgica asturiana, Luis Adaro Ruíz-Falcó (1914-2006), dio a la luz un importante documento depositado en el Archivo General de la Marina Álvaro de Valdés (AGMAV) en el que se mencionaba el envío de unos carbones de Langreo al laboratorio de la Escuela de Artillería de Segovia, con el fin de que fuesen analizados por Proust y estudiase si podrían ser utilizados como combustible en los hornos de fundición de hierro recién instalados enTrubia. A pesar de ello, se lamentaba de no haber podido localizar los resultados de dichos análisis químicos (Adaro, 1981).

La digitalización en los últimos años de un buen número de publicaciones y revistas científicas de finales del siglo XVIII y del XIX, ha permitido hacer un rastreo minucioso de la obra escrita de Proust y la localización de dos de sus escritos que permanecían completamente olvidados, en los que hace referencia a los carbones asturianos, describiendo en uno de ellos los distintos tipos analizados, así como los resultados obtenidos, y comparándolos con los ingleses, los de Bélmez (Córdoba) y los de Villanueva del Río (Sevilla). Dada la repercusión internacional que tuvieron en su momento y su interés para un mejor conocimiento de la historia minero-industrial de Asturias, en el presente artículo se dan a conocer, enmarcándolos en el contexto científico-técnico de la época.

\section{El químico francés Louis Joseph Proust, uno de los padres de química moderna}

Louis Joseph Proust (Angers, 1754-1826) (Fig. 1) es considerado como uno de los padres de la química moderna por haber enunciado la Ley de las proporciones definidas, que también recibe su nombre. Es por ello que su trayectoria vital resulta, a grandes rasgos, bien conocida, disponiéndose de numerosos textos que glosan toda su biografía (Bussy, 1826; Go- 
dard-Faultrier, 1852; Silván, 1953; Mauskopf, 1975; Portela, 1983; Wisniak, 2012), o ciertos aspectos concretos de la misma (Fujii, 1986; Gago, 1992; Puerto, 1994; Fournier, 2012). No obstante, algunos de sus trabajos sobre determinadas cuestiones han pasado más desapercibidos y ofrecen un sugestivo campo de investigación a los interesados en la historia de la ciencia. Tal es el caso de sus ensayos con los carbones vegetales y minerales con el fin de poder establecer su combustibilidad comparativa con vistas a su utilización en la fundición metalúrgica.

Formado inicialmente como farmacéutico, Proust consagró pronto toda su atención al campo de la investigación, la experimentación química y sus aplicaciones prácticas, llegando a ser reconocido como un reputado analista, tanto de compuestos orgánicos como inorgánicos. Su actividad profesional tuvo lugar en un periodo de tiempo crucial en el que la química se empezó a configurar como ciencia moderna y en el que los estudios llevados a cabo por Antoine-Laurent de Lavoisier (1743-1794) sobre la combustión y sus iniciativas para reformar la nomenclatura empleada hasta entonces, junto con otros avances en la química pneumática, multiplicaron sus aplicaciones prácticas en actividades industriales como la metalurgia, la alfarería, la fabricación de vidrio y tintes o el curtido de pieles, entre otras.

Puede resultar llamativo que la mayor parte de la carrera profesional de Proust se desarrollara en España, si bien en aquel momento el gobierno había decidido proteger y promocionar la enseñanza de la incipiente ciencia química con el fin de atender las perentorias necesidades del ejército y la marina, así como para dar respuesta a algunas demandas sociales. Para ello, se pensionó a un grupo de aventajados jóvenes estudiantes al objeto de que completaran su formación en el extranjero, y se contrató a algunos químicos experimentados para que enseñaran y divulgasen sus conocimientos en las nuevas instituciones científicas nacionales (García y Bertomeu, 2003; Gago, 1988a). Como resultado de esta política, Proust vino por primera vez a nuestro país en el mes de noviembre 1778, contando tan solo con 24 años, para hacerse cargo de la cátedra de química del Real Seminario Patriótico Vascongado (Vergara, Guipúzcoa), creada ese mismo año a instancias de la Sociedad Bascoganda de Amigos del País y financiada por la Secretaría de Estado de Marina (Silván, 1953).

En el aspecto educativo, Proust era un firme detractor de los métodos escolásticos y consideraba que enseñar la química con palabras, en lugar de con experimentos, suponía invertir el método de instruir propio de dicha ciencia, "sustituyendo el arte de aparentar al de demostrar" (Proust, 1791: XXXII). Es por ello que durante los primeros meses se dedicó a aprender castellano y a instalar un laboratorio, para el que se adquirió el más moderno instrumental de la época en Paris y Londres (Gago, 1978). Sin embargo, solo impartió docencia durante un curso completo, ya que en junio de 1780 regresó precipitadamente a París debido a la incoación de un proceso inquisitorial en su contra (Esteva y Espinosa, 1990).

Cuatro años después, el Real Colegio de Artillería de Segovia creó una nueva cátedra de química y metalurgia. Para cubrirla, el conde de Aranda, embajador por aquel entonces en Francia, se dirigió al célebre Lavoisier, quien le propuso como candidato a su amigo Proust (Fournier, 1999). Éste aceptó el encargo a comienzos de 1785 , pero su llegada a Segovia se retrasó hasta el mes de febrero del siguiente año. Al igual que hiciera en Vergara, para poder impartir docencia requirió la construcción previa de un laboratorio de química que siguiera el modelo de la École de minéralogie et de métallurgie docimastique de París (Marcelo, 2011), por lo que también sería dotado espléndidamente, aunque su conclusión se demoró hasta 1790.

Durante el tiempo que duraron las obras y se consiguió la dotación instrumental, Proust llevó a cabo varias comisiones encargadas por el gobierno y después dedicó un año completo a la investigación -"todo mi tiempo de día y de noche, nec mora, nec requies"-, llevando a cabo más de cuatrocientos "procederes" -transcripción empleada por Proust del término francés "procédés", procesos- que serían la base de su labor docente (Proust, 1791). Con ellos dio forma a dos volúmenes titulados Anales del Real Laboratorio de Química de Segovia, publicados en 1791 y 1795. Era éste un ambicioso proyecto editorial del científico galo, con el que daba cumplimiento a su compromiso de difundir el conocimiento adquirido con sus experimentos y ofrecía a los cultivadores de la química, tanto de España como de América, una plataforma en la que exponer sus descubrimientos. Sin embargo, de los 42 y 16 artículos que componen, respectivamente, cada uno de los tomos, solo dos fueron escritos por sendos capitanes del Real Cuerpo de Artillería, hecho que, sin duda, contribuyó a que la publicación no tuviera continuidad.

Disponiendo ya del laboratorio y del primer tomo de los Anales, la enseñanza se inauguró el 1 de febrero de 1792. Al dar noticia de este acontecimiento, el Mercurio de España del siguiente mes anunció (p. 254) que "conociendo S.M. quan útil y aun necesario sea el citado estudio de la chîmia para los progresos de la agricultura, metalurgia, farmacia y otras ciencias, y para la perfeccion de muchas artes y oficios, ha sido su Real intencion en la ereccion de este estable- 
cimiento, facilitarlo á todos sus vasallos, de qualquier estado ó condicion que sean; y en conseqüencia ha ordenado que se admitan todas las personas que lo deseen á estos cursos".

Con todo, y a pesar del decidido apoyo real, durante su estancia en tierras segovianas Proust volvió a tener problemas con la Inquisición, al reabrirse el expediente iniciado años atrás en Vergara, y se llegó a decretar su encarcelamiento. Pero su detención quedó sin efecto al prescribirse en 1797 que los extranjeros de cualquier religión pudieran residir en España sin que el Santo Oficio tuviera jurisdicción sobre ellos (Gago y Mauskopf, 1984). Esta disposición facilitaría que al año siguiente se casara con Anne Rose Châtelain d'Aubigné, súbdita francesa que residía en aquella ciudad castellana como refugiada. El matrimonio no llegó a tener hijos (Wisniak, 2012).

Debido a su carácter independiente, sus relaciones con las autoridades militares tampoco debieron ser todo lo armoniosas que hubiera sido deseable $y$, resentido en su salud, el desarraigo hizo mella en su ánimo. Así se desprende del contenido de una carta dirigida a su hermano a finales de 1798, en la que le manifestaba que creía tener el pecho atacado y que toda su ambición era regresar a su granja de Canterie (Comuna de Briollay, Departamento de Maine y Loira) para llevar allí "la vida más sencilla y relajada de todas, aquella, en pocas palabras, de cualquier hombre que se contenta con su sopa, su trozo de tocino y el pescado que pesca", a lo que añadía que se iría de España si no le surgía un compromiso más favorable, abandonando un país que le resultaba muy ajeno, pues nunca habían dejado de tratarle como a un extranjero (David, 1938).

Así, sus clases solo duraron tres cursos, y para tratar de que permaneciera al servicio de Carlos IV, a finales de 1798 el gobierno le ofreció dirigir la nueva Real Escuela Práctica de Química a establecer en Madrid, en la que se unificaría el laboratorio de Segovia con los dos que, sin ninguna conexión entre ellos, mantenían en la capital los Ministerios de Estado y Hacienda. Para agasajarle aún más, el establecimiento fue dotado con gran magnificencia. Casi todos los utensilios se hicieron de platino y el rey se los dio en propiedad (Bussy, 1826).

Proust comenzó a impartir sus lecciones públicas en el naciente establecimiento a finales de 1800 (Fraga, 1995) y continuó su labor divulgadora participando, junto con el mineralogista alemán Christian Herrgen (1765-1816), el botánico valenciano Antonio José de Cavanilles (1745-1804) y el químico burgalés Domingo García Fernández (1759-1829), en la creación de los Anales de Historia Natural, primera revista española de este ramo, que en enero de 1801 cambió su nombre por el de Anales de Ciencias Naturales.

Su labor docente y divulgadora se interrumpió a finales de 1806, fecha en la que obtuvo un permiso para viajar a Francia por motivos familiares, aunque por razones no del todo claras decidió permanecer allí. En su ausencia, Gregorio González de Azaola (1776-1840), que ocupaba la plaza de ayudante en la Escuela, se hizo cargo de ella. Pero a raíz de la invasión napoleónica de 1808 el laboratorio fue saqueado, lo que zanjó definitivamente cualquier posibilidad de que Proust regresara, poniéndose punto final, así, a su etapa española.

Una vez en Francia, continuó algunas investigaciones que ya tenía iniciadas, publicando, entre otras, una extensa memoria sobre la pólvora y, al recibir en 1811 el apoyo del reputado químico sueco Jöns Jacob Berzelius (1779-1848), resolvió la encendida controversia que mantuvo durante varios años con su colega Claude Louis Berthollet (1748-1822), partidario de una ley de proporciones indefinidas para las combinaciones químicas (Koper, 1965).

Tras la muerte en 1819 de su hermano Joachin, Proust pasó a regentar la farmacia familiar que aquel poseía en la localidad de Angers (Departamento de Maine y Loira), en la que su padre le había iniciado en esta disciplina, y continuó trabajando en su laboratorio tras su venta dos años después (Fournier, 1999). En esta última etapa de su vida se sucedieron los reconocimientos públicos, siendo elegido en 1811 miembro de la Sociedad Agrícola de Turín; en 1816 del Instituto de Francia; en 1819 de la Real Academia de Ciencias de Nápoles y caballero de la Legión de Honor, y en 1820 miembro de la Academia Real de Medicina francesa. Ese mismo año Luis XVIII le concedió una pensión de 1.000 francos oro. El 5 de julio de 1826 falleció de un ataque de asma en su localidad natal (Wisniak, 2012).

A finales del siglo XIX y principios del XX, la labor formativa de Proust fue duramente cuestionada por no haber conseguido formar, con los medios y privilegios de los que dispuso, un grupo de discípulos capaces de desarrollar una escuela química española (Bonet, 1885, 1886; Rodríguez Carracido, 1897; Fragés y Virgili, 1909). Este tópico fue rebatido por investigaciones posteriores (Gago, 1988; Puerto Sarmiento, 1994), aunque no cabe duda de que la Guerra de la Independencia y la posterior represión de Fernando VII interrumpieron el proyecto de institucionalización científica diseñado por Proust en el plan aprobado para la Escuela Práctica de Química en 1803.

No obstante, el químico francés también fue contratado para que con sus conocimientos estudiase y mejorase muchos aspectos científico-técnicos de varias industrias nacionales, como la armamentística, la minera-metalúrgica, o la textil, entre otras. En este 
sentido, la mayoría de sus estudios sobre determinados procesos productivos o industriales indican las posibles mejoras de que eran susceptibles, ya fuese para conseguir productos finales de mejor calidad, o sobre la forma más adecuada para producirlos (Baig, 2010). Cabe señalar que también contribuyó de forma decisiva a la adaptación a nuestra lengua de la moderna terminología química que se comenzaba a normalizar en aquella época (Florián, 1999). Y tampoco se puede olvidar que llevó a cabo en la Academia de Segovia las primeras pruebas para implantar la aerostación militar en el arma de artillería, siendo nuestro país el primero en el mundo en contar con aerosteros militares (Herrero, 1993).

\section{Los análisis del carbón y la fundición del hierro en la época de Proust}

El carbón de leña, obtenido por la carbonización de la madera mediante pirólisis bajo una capa de tierra, ha sido utilizado desde tiempo inmemorial como combustible al ser su poder calorífico mucho mayor que el de aquella. Pero en el siglo XVII, el acelerado deterioro de los montes, provocado por la deforestación, obligó a dirigir la vista hacia la hulla, de la que existían inmensos yacimientos en algunos países. Sin embargo, en estado bruto ésta no resulta adecuada para los usos de la industria metalúrgica, por lo que en la búsqueda de alternativas viables se llegó, de forma totalmente empírica, a la invención del coque.

Obtenido por medio de la destilación destructiva de carbón bituminoso, se pueden encontrar distintas referencias sobre la fecha y el lugar de invención de éste combustible. No obstante, el desarrollo real de su producción se produjo en Inglaterra a mediados del siglo XVIII, tras comprobarse que resultaba óptimo para elaborar hierro en altos hornos, debido a sus propiedades físicas y químicas que le permiten intervenir como combustible, agente reductor, carburante y soporte permeable, soportando las condiciones extremas del proceso (Díez, 2013).

Richard Kirwan (1733-1812) señalaría, acertadamente, que el conocimiento exacto de los componentes de las diferentes especies de carbón mineral resultaba de gran importancia para extraer de cada especie todas las ventajas que era capaz de ofrecer, así como para comparar las diversas clases que ofrecían los diferentes países con el fin de emplear aquel que resultase más adecuado para los fines propuestos. Sin embargo, también reconocía que eran sustancias que resistían los modos habituales de análisis (Kirwan, 1796).

Por aquel entonces, el carbón recibía el calificativo de "bituminoso" cuando contenía una parte de sus- tancia que podía ser volatilizada por calor, ya que era parecida al betún verdadero. La cantidad de sustancia bituminosa podía diferir considerablemente de unos a otros, pero no se pudo reconocer ninguna diferencia esencial entre ellos, y había tantas variedades intermedias con pequeñas gradaciones de contenido que era imposible establecer una línea de distinción. Tampoco resultaba reconocible por el contenido de hidrógeno, por lo que la manera práctica de diferenciarlos consistía en que producían diferentes cantidades de sustancia volatilizable cuando se calentaban. Pero estos productos volátiles eran difíciles de quemary, si no se adoptaba ninguna disposición especial al respecto, salían junto con el humo por la chimenea del horno sin que pudieran ser aprovechados como fuente de calor. Otra característica reconocible era que cuando un tipo de carbón se calcinara, dejaría un residuo carbonoso fijo -propiamente el coque-, que representaba una porción considerable de su peso. Así, el procedimiento científico habitual para diferenciar unos de otros consistía en realizar un análisis químico en el que, tras destilarlos, se deducía el contenido de ceniza y se determinaba la relación del residuo carbonoso fijo respecto a la porción volatilizable.

Desde mediados del siglo XVIII, un gran número de naturalistas de toda Europa se dedicaron a hacer análisis de carbones, obteniendo resultados muy dispares. Uno de los más activos, Giovani Fabbroni (1752-1822) señalaría que en las diversas antracitas había cantidades variables de cenizas, compuestas por diferentes ingredientes y de distinta naturaleza, pero que tales desigualdades resultaban de cierta diversidad en su constitución, a veces no de la especie, sino de la misma pieza que se analizaba, concluyendo que no había nada más erróneo que fijar como regla general lo que resultaba solo de un análisis especial (Fabbroni, 1790). No resulta extraño, pues, que el célebre JeanFrançois-Clément Morand (1726-1784) afirmara que de todas las producciones de los tres reinos, el carbón de piedra era el que presentaba más singularidades y dificultades en el análisis (Morand, 1776).

Mientras tanto, en España se seguían aplicando métodos sensoriales o, en todo caso, empíricos para comprobar la calidad de los carbones que se iban descubriendo en distintas provincias. Como ejemplo más esclarecedor, Eugenio Larruga (1747-1803), que en 1782 fue encargado por la Real Junta general de Comercio, Moneda y Minas de todos los asuntos relativos al descubrimiento y laboreo de estas últimas, señala que ese mismo año se remitieron al industrial irlandés Enrique Doyle unas muestras de un carbón hallado en las montañas de Santander para que practicase los correspondientes experimentos sobre su calidad e informase al respecto. Éste respondió que 
a pesar de que los inteligentes en el carbón de piedra distinguían y conocían su calidad "sin más experimentos que por el tacto y la vista", no le había parecido suficiente este superficial informe para dar respuesta a la Real Junta en un asunto de tanta importancia, por lo que adjuntaba varias certificaciones con las opiniones probadas de expertos en la materia. Respecto a la sanidad del referido género, aportó los informes favorables emitidos por los médicos Casimiro Gómez-Gutiérrez Hortega (1741-1818) y Diego Porcel; sobre la inocuidad de su uso en chimeneas, los resultados de la positiva experiencia practicada en la casa del conde de Pietra Santa; y respecto a su idoneidad para la utilización en fraguas y ferrerías, las elogiosas opiniones de Juan de Selva, maestro herrero y cuchillero que llevaba trabajando tres años con el carbón de piedra de Inglaterra en el astillero de Cartagena, y de Francisco Salamanca, maestro cerrajero de la Corte (Larruga, 1793: 132-138).

En este contexto, el primer español que realizó análisis de carbones fue el ingeniero de Marina Fernando Casado de Torres (1757-1829), que en 1789 fue enviado por el gobierno a una misión de espionaje industrial en Gran Bretaña con el fin de informarse sobre el procedimiento para elaborar coque y contratar a algún minero competente. El 22 de enero del siguiente año remitió un extracto de los experimentos que había realizado al ministro de Marina Antonio Valdés (1744-1816), indicando: "sobre ser un trabajo enteramente nuevo, descubren felizmente los datos que nos faltaban para determinar, con exactitud, la cantidad de aire atmosférico que debe emplearse en la ignición de los carbones minerales, para que la descomposición del aire vital produzca el mayor efecto posible en las fundiciones; problema que pienso haber resuelto completamente en la teoría que doy de la combustión del coak". Concluía afirmando que solo le faltaban determinar las dimensiones que deberían tener los hornos para conseguir que la circulación del aire fuera constante, cuestión que no había podido resolver porque dicha operación requería disponer de un aparato costoso para hacer experimentos (Adaro, 1981).

Acreditado por los conocimientos adquiridos en la materia, Casado se convirtió en el técnico de referencia para todas las cuestiones relacionadas con el carbón. Así, tras ser enviado al Principado de Asturias en el mes de julio de 1791, informó de nuevo a Valdés, señalando: "He corrido más de una vez los concejos de este Principado en que hay minas de carbón, y reconocido cuantas están puestas en cultivo; he abierto y beneficiado otras muchas; he observado la naturaleza de sus carbones y averiguado por medio del análisis el mérito de cada especie de ellos" (Huici, 1931). Ese mismo mes analizó un cajón de carbón desazufra- do que le había presentado Antonio Josef del Castillo (?-?), apoderado y socio de la Compañía de Pumarejo que pretendía obtener una contrata para el suministro de las Reales Fábricas de La Cavada (Cantabria). Posteriormente, el 21 de diciembre de 1793 Casado remitió a Valdés dos muestras de carbón de las minas de Langreo para que el rey pudiese conocer su excelente calidad, indicando: "Cada uno de ellos lleva pegado un papelito, con la explicación correspondiente de sus cualidades, y esencia de sus principios constituyentes, arreglada a los análisis que tengo hechos de los carbones de este principado en enero y febrero de 1792; $y$ en especialidad de los de las 83 minas, que beneficia por su cuenta la Real Armada" (Adaro, 1981). Asimismo, en 1797 le envió los resultados de los análisis del carbón de la mina de Viérnoles (Cantabria), indicando los porcentajes de coque, de "flema alcalina" $y$ "aceite caustico" obtenidos (Alcalá-Zamora, 1974)

Por otra parte, la fabricación de coque metalúrgico también entrañaba cierta complejidad, ya que conviene que presente una buena resistencia mecánica, así como una textura porosa adecuada para que su reactividad frente a los gases desprendidos sea idónea. Pero estas características derivan de microestructuras cristalinas opuestas, lo que requiere la búsqueda de un equilibrio difícil de conseguir (Díez, 2013), empleándose en la actualidad mezclas complejas en las que se pueden llegar a combinar más de diez tipos diferentes de carbones minerales en distintas proporciones.

Ya en 1774 Antoine-Gabriel Jars (1732-1769), que había viajado a Gran Bretaña para conocer la manera de preparar el coque, señalaba que el proceso parecía aparentemente fácil, pero que requería de una práctica bien entendida y muchas precauciones, pues de lo contrario solo se obtenían coques imperfectos e incapaces de ser empleados de manera útil (Jars, 1774). Dieciséis años después, Isnard Gazeran (?-?), reconocía que no todos los carbones de piedra tenían la misma naturaleza como para obtener de ellos un coque de calidad, y recalcaba que distintos carbones de piedra desazufrados de igual forma podían dar hierro con resistencias muy dispares (Gazeran, 1790).

Entrado el siglo XIX, Auguste Henri de Bonnard (1781-1857) señalaría que los inconvenientes a superar para obtener un buen coque eran de tal naturaleza, que los conocimientos científicos y técnicos de la época no podrían remediarlos de manera adecuada, aunque se intentase mejorar el producto perfeccionando el proceso de carbonización (Bonnard, 1805). A la vista de ello, Gazeran recomendaría analizar con cuidado el carbón que se pretendiera convertir en coque, utilizando aquel que contuviera poco sulfuro de hierro y solo dejara del 1 al $3 \%$ de cenizas. En caso de que no se 
dispusiera de medios para analizarlo, proponía utilizar aquel que cumpliera la condición de que 16 partes del mismo descompusieran completamente, por detonación, 100 partes de nitrato de potasa. En todo caso, aconsejaba desulfurar por separado y al aire libre los carbones que contuvieran sulfuros y dejaran poca ceniza, carbonizando solo aquellos que contuvieran betún por procedimientos análogos a los empleados con el carbón vegetal (Gazeran, 1810).

Otro reto para los químicos de la época era establecer el papel que realmente desempeñaba el carbón en el proceso de fundición del mineral de hierro, ya que se trata de una reacción termoquímica compleja en la que se combinan la reducción, la reoxidación, la carburación y la descarburación. En 1773, Antoine Baume (1728-1804) afirmaba que el acero nunca había sido examinado químicamente, por lo que no se podía reconocer en qué se diferencian sus propiedades de las del hierro. Ocho años después, Torbern Olof Bergman (1735-1784) demostró que la diferencia entre el hierro dulce, el hierro colado y el acero se debía principalmente a la presencia de carbono extraído del carbón vegetal durante la fundición, pero al adoptar la explicación flogística de la combustión, su teoría quedó obsoleta tras la publicación en 1786 de las Reflexiones de Lavoisier. Ese mismo año Berthollet, Gaspard Monge (1746-1818) y Alexandre-Théophile Vandermonde (1735-1796) descubrieron que el carbono se combinaba con el hierro en diferentes proporciones, dependiendo de la temperatura y del trabajo que se aplicara al hierro.

Pero la diversidad de factores críticos que intervienen en el proceso y la dificultad técnica que entrañaba controlarlos adecuadamente, eran todavía barreras infranqueables para los científicos de aquella época. Así lo reconocería Proust en el discurso que pronunció en 1792 en la inauguración oficial del laboratorio de química del Real Colegio de Artillería de Segovia, al manifestar a los jóvenes cadetes: "Lo que hallaréis, a la verdad, más particularmente digno de toda vuestra atención en el estudio de la Chimia, será los cortos progresos que ha hecho la parte Chimio-Metalúrgica de la Artillería en toda la Europa; notaréis la multitud de problemas que producen las operaciones necesarias para la formación de un cañón y quedaréis admirados al ver (como oportunamente dice Don Thomas Morla, en su Tratado de Artillería) que la verdadera purificación de los metales, el modo de aligarlos, y sus proporciones respectivas, aunque operaciones practicadas diariamente por una rutina de muchos siglos, son aún en el día, otros tantos problemas que quedan por resolver en nuestras fundiciones" (Proust, 1792, p. 41).

\section{El carbón en la obra escrita de Proust}

En 1778, y tras haber obtenido la plaza de farmacéutico jefe en el Hospital de la Salpétriere (París), Proust redactó un extenso artículo titulado Observations sur des Pyrophores sans alun, sur l'inflamation des Huiles \& des Charbons, que apareció recogido en el Journal de Médecine, Chirugie et Pharmacie (L: 44-59 y 131142), así como en Observations sur la Physique, sur I'Histoire Naturelle et sur les Arts (XIII: 432-442). Intervenía así en la controversia sobre aquellas sustancias que tienen la propiedad de inflamarse con el aire, al ser éste un tema directamente relacionado con el de la combustión, que atraía el interés de químicos de la época. En él demuestra ya su carácter independiente, al discutir las opiniones que algunos prestigiosos colegas habían expuesto con anterioridad sobre este tema, pero no entra a analizar la composición de los carbones.

Así pues, no fue hasta 1791 cuando, encontrándose ya al servicio de Carlos IV, evidenció su atención por el papel que desempeñaba el carbono en los procesos metalúrgicos, al incluir en el primer tomo de sus Anales del Real Laboratorio de Química de Segovia (1791) el opúsculo titulado Sobre la combinación del carbón con el plomo (pp. 45-50). El nombre del elemento químico carbono ya había sido acuñado tres años antes por Louis-Bernard Guyton de Morveau (1737-1816), Lavoisier, Berthollet y Antoine François de Fourcroy (1755-1809) en su revolucionario Méthode de nomenclature chimique (1787). Al haber obtenido ácido carbónico por combustión del carbón vegetal, dedujeron que aquel tenía que derivar necesariamente de la "materia carbonácea pura", a la que denominaron carbono, justificando su decisión de la siguiente manera: "para poner aún más precisión en la denominación de este radical, distinguiéndolo del carbón en la aceptación vulgar, aislándolo, por el pensamiento, de la pequeña porción de materia extraña que normalmente contiene, y que constituye la ceniza, le adaptamos la expresión modificada de carbono (carbone en el texto original en francés), que indicará el principio puro y esencial del carbón, y que tendrá la ventaja de precisarlo con una sola palabra, para evitar cualquier ambigüedad".

En su artículo, Proust refiere el descubrimiento de la unión del carbón (sic) con el hierro que tiene lugar en el acero, realizado en 1786 por los académicos Berthollet, Monge y Vandermonde, y recomienda la traducción al español del Bergwerks Lexicon (1788-1789) de Sven Rinman (1720-1792), pero no parece estar al tanto del nuevo nombre dado al elemento químico. Así, apoyándose en las leyes de la proporción y elección que presidían todas las uniones químicas por afinidad, creía que solo la "pura materia del carbón", 
sin las tierras y las sales con las que estaba mezclada, se podía combinar con los metales, a lo que añadía que se trataba de una sustancia todavía desconocida que los químicos debían clasificar entre los cuerpos simples o elementales. También entendía que no se le podía negar la propiedad de pasar al estado líquido y al vaporoso.

En ese mismo volumen de los Anales aparecieron otras dos memorias relacionadas con el tema que nos ocupa. La primera de ellas, titulada Sobre las bombas de S. Sebastián de Muga en Cataluña (pp. 51-59), es fruto de la comisión que en 1787 le encomendó Francisco Antonio de Lacy (1731-1792), director del Real Colegio de Artillería de Segovia, con el fin de que examinara "aquellas operaciones que se practican en grande para afianzar con más perfección sus ideas en las operaciones pequeñas de Chimica y Metalurgia en la parte de Fundiciones" y que le llevaría a visitar ese mismo año las fábricas de bronce de Barcelona y de hierro fundido de San Sebastián de la Muga (Gerona). Proust comienza refiriendo que los químicos suecos y franceses habían aclarado que los colores grises, negros y los matices intermedios que se notaban en las fundiciones de hierro provenían de la diferente cantidad de carbón (sic) que se unía al hierro. Tras explicar estos procesos, analiza las causas que motivaban la preocupante formación de grietas y cavidades en la masa de metal fundido, que hacían que los productos moldeados se pudieran romper, y propone el remedio para este problema (Baig, 2010, p. 26).

En la segunda, Indagaciones para perfeccionar el bronce para la artillería (pp. 313-317), aventura que llegaría algún día en el que en las fundiciones del rey se refinaría el cobre y se fundirían los cañones con carbón de piedra. Aporta el dato de que en 1781 ya se habían fundido en Sevilla dos piezas de a 24 con cobres refinados en Puerto Real con carbón mineral y que salieron tan bien como aquellas en las que se había empleado carbón de brezo. Indica, asimismo, que esta técnica se aplicaba de forma habitual en Inglaterra y que no entrañaba ningún misterio.Y aunque creía que si se intentaba hacer en España "la rutina opondría algún tiempo sus escrúpulos" y que los fundidores argüirían en su contra la presencia de azufres, ácidos y vitriolos que se atribuían al carbón de piedra, no dudaba de que finalmente conseguirían hacer la sustitución si se les facilitaban algunos ensayos. En todo caso, consideraba imprescindible que los jóvenes que aprendían el método de fundir los cañones estudiaran francés, inglés y alemán para poder aprovechar las enseñanzas de los buenos libros, y que deberían visitar las fábricas metalúrgicas extranjeras.

Cabe señalar que en el segundo tomo de los Anales (1795) incluyó el Ensayo sobre los medios de reco- nocer el grado de afinación de los cobres (pp. 7-18), en el que manifestó su fe inquebrantable en la capacidad de la química para solventar las incógnitas aún pendientes para comprender el proceso de fundición, señalando: "Sin las luces que subministra esta ciencia a todas las artes, sin los principios tan claros que deduce de los análisis de los cuerpos naturales, jamás llegará la Artillería a establecer un método permanente y razonado que sirva en la práctica de sus fundiciones $y$ esté fundado enteramente en el uso de los mismos cuerpos".

En 1799 Proust publicó dos breves artículos en el Journal de Physique, Chimie, d'Histoire Naturelle et des Arts (JPCHNA) relacionados con el carbón. En el titulado Sur la proportion du charbon dans quelques bois, et sur celle des charbons de terre (XLVIII: 469471) comienza refiriendo el porcentaje de carbón vegetal que obtuvo a partir de diez tipos de madera -roble verde, fresno, sauce, olmo blanco y negro, pino, roble, nogal, boj y gaiac- que resultaron comprendidos entre el 17 y el $25 \%$, y comparativamente señala que cualquier carbón mineral de buena calidad ofrecía de un 70 a un $80 \%$ de coque y menos cenizas que el carbón de pino, poniendo como ejemplo los carbones de Asturias y Andalucía, con un 2 o 3\%, y los de los alrededores de Almadén (se refiere a los de Bélmez, que él sitúa en Extremadura) con un 6 o 7\%. Después expone su sospecha de que entre los productos de la destilación de los carbones de piedra pudiera encontrarse el ácido succínico en pequeñas cantidades, pero lo que considera más interesante de verificar, y todavía no había podido hacer, era lo que consideraba una combinación muy peculiar de la materia carbonosa con una porción de azufre, distinta e independiente de cualquier mezcla de pirita. Proust llevó a cabo estos análisis químicos para intentar resolver los problemas surgidos al fundir hierro a la inglesa, es decir, con coque, en las recién creadas fábricas de armas y municiones de Oviedo y Trubia (Asturias), como señalaremos más adelante, y los presentaba aquí como avance de una publicación posterior más detallada.

En la siguiente monografía, encabezada con el epígrafe Sur le phosphure du charbon (XLIX: 219-220), describió brevemente los experimentos que había realizado para demostrar la afinidad del fósforo por el carbón (carbono), señalando que todavía no se habían establecido las proporciones de la nueva combinación, ni reconocido si tenía propiedades útiles.

En esta misma revista fue donde publicó en 1806 la extensa memoria denominada Faits pour servir à I'Histoire des charbons de terre (LXIII: 320-338), en la que presenta los resultados de sus análisis realizados con diferentes carbones de piedra de España, entre los que figuraban varios procedentes de distintas mi- 
nas asturianas. También aprovechó este escrito para aportar su opinión en la polémica científica del momento sobre el origen del carbón de piedra, así como para exponer sus experimentos y reflexiones sobre el óxido de carbono, los carbones deshidrogenados, el azabache y la turba. Todo ello hace que la estructura del documento resulte un tanto enrevesada.

Al comienzo del escrito enumera las proporciones de coque obtenidas por algunos de sus colegas mediante la destilación de carbones, indicando que el director de la École des mines, Balthazar-Georges Sage (1740-1824), había conseguido entre un 59 y un $60 \%$ con los de las minas de Decize (Departamento de Nièvre, Región de Borgoña); Berthollet de un 76 a un $77 \%$ con los de la de Cévénnes (Departamento de Gard, región de Occitanie), y Antoine de Gensanne (?-1780) un $75 \%$ con el extraído en la denominada mine de la forét -mina del bosque-. Tras estos antecedentes, aporta una exhaustiva relación de los resultados que había logrado empleando diferentes carbones españoles y un tipo de carbón procedente de Inglaterra que se utilizaba en los hornos de las minas de Almadén (Tabla 1). Estos ensayos los llevó a cabo destilando las muestras a fuego desnudo en recipientes cerrados (Delamétherie, 1814: 258).

Además, dejó señalada la existencia de carbones en Ripoll (Cataluña), Montalbán (Aragón) y Reinosa (Castilla, actualmente Comunidad Autónoma de Cantabria), aunque sin especificar en estos casos ninguna cantidad de coque, de lo que se deduce que no llegó a disponer de estas muestras, o no pudo llevar a cabo su destilación por algún otro motivo.

De los diez experimentos que realizó, solo tres se hicieron con muestras procedentes de fuera de Asturias: el carbón inglés, el de Bélmez y el de Villanueva del Río. Una buena parte de los carbones asturianos procedían de los concejos de Langreo -Fondón, Langreo y Rionda- y Siero -Lieres-, que habían sido explotados, respectivamente, por las Reales Minas de

\begin{tabular}{|l|l|}
\hline Carbón Inglés & $64 \%$ \\
\hline De Lieres Asturias & $60 \%$ \\
\hline Del Fondón Asturias & $64 \%$ \\
\hline De Bélmez en Extremadura (sic) & $65 \%$ \\
\hline Villanueva cerca de Sevilla & $68 \%$ \\
\hline De Quirós Asturias & $70 \%$ \\
\hline De Las Cámaras Asturias & $70 \%$ \\
\hline De Langreo en Asturias & $75 \%$ \\
\hline De Rionda en Asturias & $76 \%$ \\
\hline De Riosa en Asturias & $77 \%$ \\
\hline
\end{tabular}

Tabla 1. Proporciones de coque obtenidas por Proust con diversos carbones.

Table 1. Coke proportions obtained by Proust with various coals.
Langreo y por la Compañía de San Luis. Pero también dispuso de algún lote extraído de criaderos próximos a la Fábrica de Trubia, como eran los de Riosa y Quirós, de los que, sin embargo, no se tiene constancia de su explotación en firme hasta bien entrado el siglo XIX. Se desconoce la ubicación de la mina que aparece denominada como Las Cámaras.

Proust señala que, en general, los carbones asturianos se presentaban como vetas de poco espesor, en las que las más grandes apenas alcanzaban las 18 pulgadas $(0,49 \mathrm{~m})$ y se encontraban encajadas entre finas capas de arcilla, siendo su disposición muy variable. A ello añade que su contenido en pirita estropeaba muchas de ellas y que resultaría muy difícil quitarla, aunque se aplicara la carbonización. Estos inconvenientes le llevaron a concluir que no sería posible establecer en Asturias fundiciones como las de Inglaterra o las de Mont-Cenis (se refiere a la de Le Creuzot), al no poderse conseguir las ingentes cantidades de combustible que se necesitarían a diario para alimentar unos hornos tan grandes (Proust, 1806a: 320-321). A continuación, incluye un cuadro comparativo en el que recoge los resultados de los análisis obtenidos con los carbones de diferentes comarcas mineras nacionales y el inglés (Tabla 2).

También consideró interesante comparar la proporción entre el producto acuoso y el aceite obtenido tras la destilación. Para este experimento empleó 3 libras $(1,47 \mathrm{~kg})$ de los diferentes carbones (Tabla 3).

Por último, mostró las cantidades que obtuvo de coque y de aceite (Tabla 4).

Como conclusión de esta comparación, Proust señalará que en los carbones españoles los productos oleaginosos eran más abundantes que el agua y resaltará las siguientes características que pudo constatar:

- La cantidad de gas era variable, como la de los líquidos.

- El "carbón real" -coque- que aportaban sus betunes estaba, por lo general, por encima del $60 \%$, oscilando, según su naturaleza, entre el 60 y el $80 \%$.

- La composición del carbón de piedra también era variable en sus productos carbonosos, oleaginosos, gaseosos, etc.

- Su producto oleaginoso era, por lo general, bastante más fuerte que el que podían aportar las maderas resinosas, como el roble, el olmo, el fresno, etc.

- En los hornos que eran capaces de utilizar el carbón de piedra como combustible, era tres veces más ventajoso que ninguna otra leña conocida, ya que dejaba el triple de materia carbonosa -coque- y sólo el índigo se podía comparar con los carbones de piedra.

- Debido a su nitrogenación, el carbón de piedra conseguía de la atmósfera mucho más fuego que el carbón vegetal. 


\begin{tabular}{|l|l|l|l|l|}
\hline \multicolumn{5}{|c|}{ Productos de cien libras de algunos carbones } \\
\hline \multirow{4}{*}{ Villanueva } & Coque & 68 libras & 8 onzas & 4 gros \\
\cline { 2 - 5 } & Productos condensados & 12 & 1 & 6 \\
\cline { 2 - 5 } & Gas desprendido & 19 & 5 & 6 \\
\cline { 2 - 5 } & & 100 & 0 & 0 \\
\hline \multirow{4}{*}{ Lelmez } & Coque & 70 & & 2 \\
\cline { 2 - 5 } & Productos & 17 & 11 & 2 \\
\cline { 2 - 5 } & Gas & 12 & 7 & 4 \\
\hline \multirow{3}{*}{ Inglés } & Coque & 75 & 0 & 0 \\
\cline { 2 - 5 } & Productos & 16 & 2 & 6 \\
\cline { 2 - 5 } & Gas & 8 & 5 & 2 \\
\hline & Coque & 64 & 1 & 0 \\
\cline { 2 - 5 } & Productos & 19 & 14 & 6 \\
\cline { 2 - 5 } & Gas & 16 & 0 & 2 \\
\hline
\end{tabular}

Tabla 2. Resultados de los análisis obtenidos por Proust con diferentes carbones.

Table 2. It was not until 1986 that Luis Adaro Ruíz-Falcó published.

- Los productos oleaginosos y gaseosos se producían tanto al aire libre como en recipientes estancos. Algunos carbones habían conseguido producir más llama que otros, por lo que, consecuentemente, serían más apropiados en los hornos donde se precisaba un gran chorro de llamas, como los que se usaban para fundir el bronce, hacer porcelana, loza, etc.

- Aquellos carbones que aportaban mayor cantidad de coque después de la destilación, durarían más tiempo en las forjas o en los hornos de reverbero.

También advertía que los carbones más ricos en aceite no eran, por lo general, los más fáciles de destilar, al menos por el método ideado por Lord Dundonald (1748-1831), ya que se fundían, se hinchaban y se fusionaban, formando una masa uniforme que costaba trabajo romper. Esta apreciación es muy importante para entender los problemas que se encontraron los fundidores de los establecimientos asturianos para emplear el coque obtenido con carbones de la región, ya que el langreano era, con mucho, el más bituminoso.

Por otro lado, Proust comentaba que el carbón de Langreo solamente dejaba un $2 \%$ de cenizas y que no era muy ferruginoso. Del de Quirós decía que también era muy bueno, pero poco abundante. Por último, destacaba otro tipo localizado cerca de la colegiata de Arbás (Villamanín, León), en las proximidades del puerto de Pajares, al que había denominado blenda "para espesar aún más la oscuridad de su origen". Se trataba de un carbón muy negro, en el que el componente carbonoso llegaba al $93 \%$ y que no contenía hidrógeno. Reconocía que se trataba de una especie de coque natural que quemaba sin desprender olores bituminosos, ni sulfurosos, y dejaba solamente un $7 \%$ de cenizas blancas.
Respecto al resto de experimentos que llevó a cabo, resulta especialmente significativo su reconocimiento del estado incipiente de la investigación científica en este campo, al afirmar: "Todavía estamos muy lejos de conocer tanto el carbón que vemos todos los días, como el carbono que nunca cae bajo nuestros sentidos".

El artículo de Proust suscitó un gran interés en aquel momento, pero también mantuvo su repercusión en el ámbito científico a lo largo de los años, como se demostrará más adelante.

En el mismo número de la JPCHNA apareció, además, su memoria Fonte de fer (LIII: 463-467) en la que, en contra de la opinión de Berthollet, insiste en la idea de que la existencia de carburo de hierro en el hierro fundido era el ejemplo de una combinación unida al exceso de uno de sus elementos, aunque afirma desconocer si se deberían colocar en la misma línea las combinaciones que estaban contenidas en proporciones constantes y las que no se encontraban sujetas a ninguna, puesto que no todos los elementos de dichas uniones eran aun suficientemente conocidos. De esta forma, consideraba que bastaba con presentarlos, de momento, como hechos incontestables, "mientras se espera que la meditación se apodere de ellos y determine finalmente el lugar que les conviene en el edificio de la ciencia".

Por último, una vez en Francia, Proust completó un estudio sobre la pólvora que había iniciado durante su estancia en Segovia. Sus experiencias y conclusiones quedaron recogidas en un extenso artículo titulado Faits pour servir a l'étude de la poudre à canon, que fue publicado igualmente por la JPCHNA en nueve entregas entre 1810 y 1813 (LXX: 320-340; LXXII: 113-126 y 265-281; LXXIII: 14-35 y 376-400; LXXIV: 203-220; LXXV: 


\begin{tabular}{|c|c|c|c|c|c|}
\hline \multirow{2}{*}{ Villanueva } & Producto acuoso & 100 & \multirow{2}{*}{ Langreo } & Producto acuoso & 100 \\
\hline & aceitoso & 262 & & aceitoso & 188 \\
\hline \multirow{2}{*}{ Belmez } & Producto acuoso & 100 & \multirow{2}{*}{ Anglais } & Producto acuoso & 100 \\
\hline & aceitoso & 138 & & aceitoso & 56 \\
\hline
\end{tabular}

Tabla 3. Proporción entre el producto acuoso y el aceite obtenido por Proust tras la destilación de diferentes carbones. Table 3. Ratio between the aqueous product and the oil obtained by Proust after the distillation of different coals.

\begin{tabular}{|l|l|l|l|l|l|l|}
\hline Inglés & Coque & 64 & Aceite & 7 libras & 0 onzas & 4 gros \\
\hline Villanueva & Coque & 68 & Aceite & 7 libras & 9 onzas & " gros \\
\hline Belmez & Coque & 70 & Aceite & 10 libras & 4 onzas & " gros \\
\hline Langreo & Coque & 75 & Aceite & 11 libras & 11 onzas & 4 gros \\
\hline
\end{tabular}

Tabla 4. Cantidades de coque y aceite obtenidas por Proust de los carbones analizados.

Table 4. Amounts of coke and oil obtained by Proust from the coals analyzed.

362-392; LXXVI: 334-352; LXXVIII: 169-206). Con él pretendía contribuir al progreso de la ciencia y al mejoramiento de la pólvora, arrojando luz "primero sobre la elección de los carbones que más le convienen, y luego sobre la proporción de este combustible que merezca preferencia por su composición". Para el caso que nos ocupa, resulta especialmente llamativo que, a pesar de su amplia experiencia en el análisis de los carbones minerales, no intentara siquiera probar su posible utilidad para la preparación de la mezcla deflagrante, alegando desdeñosamente: "el carbón destilado de los ingleses (coque) ha sido elogiado por dar mejores pólvoras; pero mientras no veamos el diario de las pruebas que constató su superioridad, y las pruebas mismas bien despejadas de las objeciones que se les pueden oponer, nos abstendremos de hablar de ello para retomar el hilo de nuestras observaciones".

Para cerrar este epígrafe, cabe señalar que Manuel Fernández de Castro (1825-1895) refiere que José Cornide Saavedra (1734-1803) incluyó en su Memoria sobre el descubrimiento de una mina de carbón de piedra en las Puentes de García Rodríguez, inserta en la publicación periódica titulada Espíritu de los mejores Diarios literarios que se publican en Europa (Tomo VIII, $\mathrm{n}^{\circ} 243$, del 26 de julio de 1790), el dictamen de Proust sobre el análisis de dicho carbón (Fernández de Castro, 1874). Sin embargo, el supuesto ensayo químico no aparece citado en esa memoria, ni figura en ninguno de los ejemplares de dicha publicación depositados en la hemeroteca digital de la Biblioteca Nacional de España, por lo que no se ha podido verificar la existencia de ese análisis de un carbón nacional atribuido al químico francés.

\section{La intervención de Proust en las fábricas de armas de Oviedo y de municiones de Trubia (Asturias)}

El deterioro de las relaciones que mantenía España con las autoridades francesas, tras el triunfo de la
Revolución, llevó al Consejo de Estado a comisionar en 1792 al ingeniero de Marina Fernando Casado de Torres para que buscase un emplazamiento adecuado y alejado de la frontera pirenaica en el que poder establecer fábricas de armas y municiones, ya que las que se encontraban en las provincias de Guipúzcoa, Vizcaya, Navarra, Barcelona y Gerona, correrían serio peligro si se produjera un conflicto bélico con el país vecino. El temor no tardó en hacerse realidad, pues al desencadenarse al año siguiente la Guerra contra la Convención, las tropas francesas ocuparon las fábricas de Eugi, Orbaiceta (Navarra) y Guipúzcoa, y destruyeron la de San Sebastián de la Muga (Gerona).

De esta forma, tras fracasar en 1793 los ensayos de fundición con coque que se realizaron en la Real Fábrica de Artillería de La Cavada, al año siguiente el gobierno ordenó construir una fábrica de municiones gruesas en Trubia y otra de armas portátiles en Oviedo (Asturias), poniendo al frente del nuevo complejo industrial militar al brigadier Francisco Vallejo (Adaro, 1986). La intención era que en ambas se utilizara el carbón de piedra de las minas de Langreo, siguiendo el proceso ya generalizado en los establecimientos de igual clase de los países más avanzados de Europa (Gran Bretaña en 1735, Rusia en 1780, Francia en 1785, Alta Silesia en 1790).

Sin embargo, el 06 de mayo de 1796 el capitán general Martín Antonio Álvarez de Sotomayor, conde de Colomera, informó al ministro de la Guerra, Miguel Joseph de Azanza, que al no haber tenido éxito las pruebas efectuadas por Vallejo en la fábrica de Oviedo, había remitido el documento de ensayos a Proust para que diera su opinión al respecto. Éste había respondido que las experiencias realizadas no eran concluyentes y que para tomar una decisión correcta sería necesario hacer nuevos análisis de los carbones, pareciendo dar a entender que ya habría llevado a cabo alguno que otro con anterioridad. Para ello, solicitaba que se le enviaran a Segovia muestras de los de Lan- 


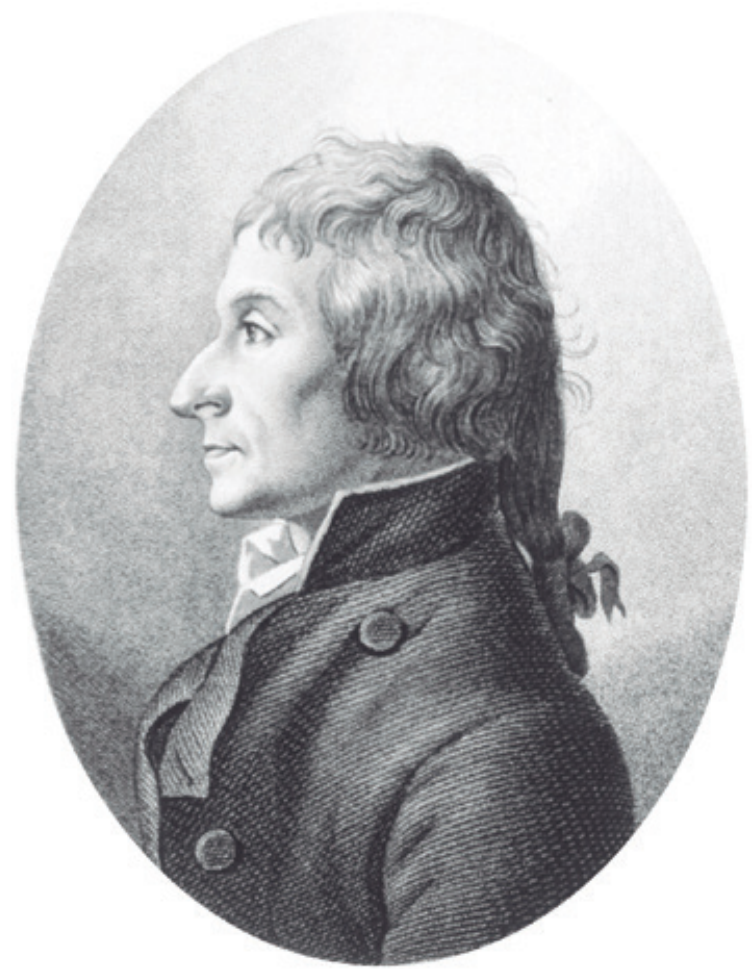

Figura 1. Louis-Josseph Proust (1754-1826)

Figure 1. Louis-Josseph Proust (1754-1826)

greo, del de Inglaterra que se encontraba depositado en los almacenes de las minas de Almadén, y del de la mina de Villanueva del Río (Sevilla). La petición del químico galo fue atendida sin demora, pues el 03 de junio el interventor de las Reales Minas de Langreo, Benito Fernández, firmó una nota en Sama en la que comunicaba el envío de 139 libras $(64 \mathrm{~kg})$ de carbón limpio de la "3. a Mina del sitio llamado del Fondón, en el distrito del Nalón del $n^{\circ} 20$. galería $D^{\prime \prime}$ y 114 1 1/2 libras $(53 \mathrm{~kg})$ del de la "4.a Mina del Fondón, en el distrito del Nalón y $n^{\circ} 22$. Galería D" (Adaro, 1981).

González de Azaola, que fue ayudante de Proust en Madrid, afirma que éste viajó a Asturias para hacer ensayos de forjar fusiles con carbón de piedra y que tuvieron éxito, de manera que en 1798 pudo presentar varios cañones de fusiles y pistolas perfectamente concluidos y experimentados que merecieron la real aprobación (González de Azaola, 1825).

En octubre de 1799 el capitán de Artillería Francisco Javier Dátoli (1766-1810) informó que ya se había podido experimentar la superior calidad del carbón de piedra asturiano en las fraguas en las que se forjaban los cañones de fusil y que su uso había sido admitido por el gremio de bayonetistas (Adaro, 1981).

En relación con este último dato, unos años después Proust reprobaría la actitud de los forjadores guipuzcoanos establecidos en Oviedo por cuenta del gobierno de aferrarse a sus costumbres, exigiendo que se les proveyera de carbón de castaño cuando tenían tan cerca las ricas minas de carbón de piedra. Consideraba una ignorante despreocupación que se hubiera aceptado esa práctica, ya que había mermado la cosecha de castañas que formaba parte de la dieta habitual de los asturianos y retrasado más de una década que se comenzara a sustituir el carbón vegetal por el de piedra (Proust, 1810).

Por lo que respecta a la Real Fábrica de municiones gruesas de Trubia, las investigaciones llevadas a cabo por Adaro en el AGMAV y el Archivo General de Simancas (AGS), permiten conocer datos de gran interés sobre este asunto. Así, entre 1795 y 1796 se construyeron dos hornos altos, denominados Volcán e Incendio. El carbón de piedra procedente de las Reales Minas de Langreo se transportaría en chalanas por el río Nalón, conforme al proyecto ideado por Casado de Torres, y se desembarcaría cerca de la fábrica. Allí mismo se llevaría a cabo la carbonización, almacenándose el coque resultante en la carbonera hasta que fuera necesario utilizarlo (AGS, Sección: Guerra Moderna, Legajo 5.724).

Para ahorrar costes, se decidió comenzar a hacer ensayos en un solo horno. De esta forma, a finales del mes de febrero de 1797 el Volcán fue cargado con coque y se le dio fuego para extraer la humedad acumulada durante las obras y comprobar el aguante de la piedra refractaria. El 11 de mayo se empezaron a hacer las pruebas que deberían permitir formarse "una idea exacta de las dosis con que conviene cargarle de las tres especies de mineral que tenemos, y hechas las varias y complicadas combinaciones, para percibir el método con que debe manejarse el horno, a fin de que se consiga con la buena producción de municiones el mejor resultado del establecimiento" (AGS, Sección: Guerra Moderna, Legajo 5.727). Pero el revestimiento refractario no resistió y fue necesario encender el Incendio. Aun así, no se lograban resultados y en agosto Ignacio Muñoz, subdirector de la instalación, reconocía que todavía se ignoraba el modo de emplear con utilidad el coque. El horno fundía el mineral de hierro, pero al sangrar el arrabio, éste se solidificaba rápidamente, por lo que no entraba en los moldes.

Ante esta situación, había recurrido nuevamente a Proust, remitiéndole unas muestras de los carbones y minerales de hierro empleados, así como de los hierros procedentes de las fundiciones realizadas con el carbón vegetal, con el coque y con la mezcla de carbón combustible. Para disponer de más información, el químico francés solicitó a Dátoli una descripción de las características y del funcionamiento del horno. El militar acató el encargo, pero consideró que sería pre- 
ferible que asistiera a presenciar personalmente las operaciones (AGS, Sección: Guerra Moderna, Legajo 5.721).

Aunque se desconoce la fecha exacta en la que Proust se desplazó a Asturias y el tiempo que permaneció en la región, lo más probable es que aprovechara el viaje que realizó en 1798 para visitar las instalaciones militares de Oviedo y Trubia, así como también alguna de las minas de carbón de piedra de Langreo (David, 1938; Proust, 1806a).

No obstante, al persistir los problemas, en 1801 se comisionó a Dátoli para que, en unión de un maestro fundidor, visitara la fundición de cañones francesa de Le Creuzot y estudiara el empleo que se hacía allí del carbón mineral. El 20 de diciembre de 1803 regresaron a Trubia provistos de abundantes datos y cálculos de lechos de fusión recopilados durante su estancia, pero ni aun así se logró conseguir fundir efectivamente con coque, por lo que se volvió a utilizar el carbón vegetal (Suárez, 1993).

Proust achacaría el fatal contratiempo a los defectos de diseño que presentaban los hornos, toda vez que no tenían altura suficiente, ni disponían de la fuerza de viento necesaria para reducir el mineral con dicho combustible, por lo que resultaba imposible que el proceso de fundición terminara correctamente (Proust, 1806b). No obstante, todo apunta a que no fueron éstas las únicas causas que impidieron obtener hierro de calidad, pues Jovellanos reseñaría que no solo el sabio Proust había sido incapaz de atinar con la fundición, sino también que "hasta ahora no está determinado si el mal resultado consiste en el tamaño o forma de los hornos, en la cantidad o calidad de las venas, en la esencia o preparación de los carbones, en las trompas o barquines, en las mezclas o fundentes, o en el método mismo de la operación" (Jovellanos, 1797).

\section{La repercusión de los análisis de los carbones de pie- dra asturianos realizados por Proust en el contexto científico europeo.}

A pesar de la falta de referencias por parte de los investigadores de la historia minero-industrial de nuestro país, los estudios de Proust sobre los diferentes carbones de piedra y, en particular, los resultados de sus ensayos, tuvieron muy buena acogida y una amplia difusión en el ámbito químico y metalúrgico europeo.

El primero que reconoció la importancia de su trabajo fue Jean-Claude Delamétherie (1743-1817), editor del célebre Journal de Physique, de Chimie, d'Histoire Naturelle et de Arts. En su Discurse Préliminaire, correspondiente al tomo LXIV publicado en enero de



Figura 2. Primera página del artículo Faits pour servir à I'histoire des charbons de terre en el Journal de Physique, Chimie, d'Histoire Naturelle et des Arts (LXIII (1806): 320).

Figure 2. First page of the article Faits pour serv à l'histoire des charbons de terre in the Journal de Physique, Chimie, d'Histoire Naturelle et des Arts (LXIII (1806): 320).

1807, hizo un repaso de los avances producidos en los diferentes ramos de la ciencia durante el año anterior, incluyendo, entre otros, un apartado titulado Du Charbón de Terre al referirse a la mineralogía. En él reproduce las cantidades de los diferentes subproductos obtenidos por Proust al destilar los carbones españoles de Villanueva, Belmez y Langreo, junto con el carbón inglés, y aprovecha las conclusiones extraídas por su colega, así como las que había expuesto anteriormente en su artículo titulado Sur la proportion du charbon dans quelques bois, et sur celle des charbons de terre para plantear su propia idea sobre el origen del carbón como resultado de la mineralización de grandes masas vegetales combinadas con el ácido sulfúrico (Delamétherie, 1807).

Ese mismo año, Alexandre Brongniart (1770-1847), en su Traité Élémentaire de Minéralogie, hizo referencia a la antracita descrita por Proust en las inmediaciones del puerto de Pajares, que contenía un 0,93 de carbón y solamente un 0,07 de arena y que los habitantes del lugar utilizaban para hacer pinturas como el negro de humo (Brongniart, 1807).

Los análisis comparativos de los diferentes carbones realizados por Proust también fueron reproduci- 




( 56 )

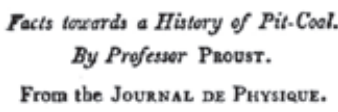

A COAL of Decise, after distillation by Sage, leât from 39 to 60 of carbonaceous residuum of English coke. $A$ cosl of Cerenés yielded Berthollet from 76 to 77 ; and that from a pit in the forest of Gensane 75. 1 have ob, tained from a coal from England 64, from Lieres 60, and from Pondon, both in Asturia, 64: from Belmez, in Fstramadura, 65 ; from Villa Nueva, near Seville, 68 ; from Quiros 70, Las Camaras 70, Langreo 75, La Rionda 70, and La Rinsa 77, all in Asturia ; from Ripoll in Catalonia, Montalban in Arragon, and Reynosa in Castile, nothing.

The environs of Madrid exhibit some vestiges of earth impregnated with bitumen, but no pit-coal, as was hoped; yet no town in Furope is at present so much in want of it. I have visited no coal-pits in Spain; except nome of thase in the fertile and picturesque province of Asturia. This country tffords, in miniature, all of the great and sublime that the traveller admires in the Alps. The coal there generally appears in reins of little thickness, the thickest are scarcely 18 inches.

These veius which are, as in all other places, situated between strata of clay, are very variable. The pyrites spoils a great quvantity ; and calcination, which, it is said will desulphurate pit-coal, would hardly be capable of clearing it; whence proceeds the impossibility of estar blishing in Asturia such foundries as they bave in England and at Mont Cenis, siace they can never bope to procure from the neighbouring land a sufficient quantity of fuel to feed their vast furnaces.



T) Journal do Phyiqiqu, T. LXIII. (Octobre 2806.) p. 5200

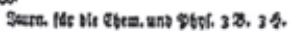

23

Figura 3. Primera página del artículo Faits pour servir à I'histoire des charbons de terre en el Journal of Natural Philosophy, Chemistry and the Arts (XVIII (1807): 161), en The Repertory of Arts, Manufactures and Agriculture (XII (LXVII)(1807): 56) y en el Journal für die Chemie und Physik (III (1807): 349).

Figure 3. First page of the article Faits pour serv à I'histoire des charbons de terre in the Journal of Natural Philosophy, Chemistry and the Arts (XVIII (1807): 161), in The Repertory of Arts, Manufactures and Agriculture (XII (LXVII)(1807): 56) and in the Journal für die Chemie und Physik (III (1807): 349).

dos de forma casi inmediata en algunas de las publicaciones científicas extranjeras más prestigiosas de la época. Así, en 1807 apareció en el Journal für die Chemie und Physik con el título Thatsachen zur Geschichte der Steinkohlen, der oxydirten Kohle, der Kohlenblende und des Gagat (III: 349-375) y en el Journal of Natural Philosophy, Chemistry and the Arts, como Facts toward a History of Pitcoal (XVIII: 161-176). También The Repertory of Arts, Manufactures and Agriculture lo difundió con dicho título en dos entregas, una en diciembre de 1807 (XII (LXVII): 56-66) y otra en enero de 1808 (XII (LXVIII): 137-148), lo que da buena muestra de la importancia que se dio a estos experimentos en el contexto internacional.

De igual forma, sus resultados fueron destacados por los alemanes Martin Heinrich Klaproth (1743-
1817) y Friedrich Wolf (1776-1832) en su Chemisches Wörterbuch -Diccionario de Química-, publicado en Berlín en cinco volúmenes (1807-1810), en la entrada correspondiente al término kohle-carbón- (III (1808): 282).

Por su parte, Delamétherie volvió a referirlos en sus Léçons de géologie: données au Collège de Fran$c e$, que vieron la luz en 1816, dentro del apartado titulado Lithantrax, charbon mineral, ou des houilles et des substances bitumineuses (pp. 50-51).

En 1821, el profesor de la Andersonian Institution y miembro de la Geological Society, Andrew Ure (1778-1857), mencionó los porcentajes de entre el 70 y el $80 \%$ de coque extraídos por Proust del carbón de piedra al definir el vocablo charcoal en su Dictionary of Chemistry of the Basis of Mr. Nicholson's (p. 310). 
Los experimentos con las hullas realizados por Proust fueron igualmente recogidos por algunos de los compendios más importantes de metalurgia del primer tercio del siglo XIX. Así, en 1812, el ingeniero de minas y profesor de la École Polytechnique, Jean Henri Hassenfratz (1755-1827) refirió en el segundo tomo de su libro La Sidérotechnie, ou l'art de traiter les minérais de fer pour en obtenir de la fonte, du fer, ou de l'acier la proporción de residuos carbonosos, o coque, que obtuvo Proust (p. 29).

Asimismo, Edmond Pelouze (1773-1847) citó dichos análisis en el primer tomo de su obra L'art du maître de forges, ou traité théorique et practique de I'exploitation du Fer, publicada en 1828 (p. 120). Y en el Handbuch der Eisenhüttenkunde-Manual de Metalurgia-, editado en cinco volúmenes por Carl Johann Bernhard Karsten (1782-1853) en 1816 y traducido al francés en 1830 por Fréderic Jacques Culmann (17871849), se citan las obras de varios químicos que habían analizado las cantidades de coque obtenidas de diferentes hullas, incluyendo entre ellas la de Proust (II ( $3^{\text {a }}$ ed., 1841), 422-423).

Estas referencias todavía se mantienen en importantes obras divulgativas y científicas pasada la mitad del siglo XIX. Tal es el caso de la prestigiosa Encyclopaedia Britannica, or Dictionary of Arts, Sciences, and General Literature, donde también se reproducen los porcentajes de coque extraídos por el químico francés en la entrada del término charcoal (VI ( $8^{\mathrm{a}}$ ed., 1854) p. 421). Asimismo, en 1863, Benjamin Horatio Paul (18271917) indica en su artículo On Destructive Destillation considered in reference to modern industrial arts, publicado en The Journal of the Society of Arts (XI, 472), en The Chemical News and Journal of Physical Science (VII, 282-295 y VIII, 56-78) y en The Engineer (XV, 313), que Proust había descrito en 1806 los aceites que se podían obtener del carbón por destilación.

Su influencia llegó incluso al ámbito judicial, pues en 1864 el Journal of Gas Lighting (XIII, 182) dio cuenta de que en el caso de Fernie y otros contra Young y otros, referido a la patente del aceite de parafina extraído del carbón, uno de los abogados incluyó entre sus alegaciones la consideración de los experimentos de Proust en el problema sobre la propiedad legal de la mencionada patente. La causa judicial fue apelada ante la Cámara de los Lores y, tal como se recoge dos años después en los Journals of the House of Lords (XCVIII, 129), para documentar el caso se remitió un exhorto al encargado de la biblioteca del British $\mathrm{Mu}$ seum para que aportase varios tratados sobre química y experimentos realizados con carbón, encontrándose entre los solicitados el artículo publicado por Proust en 1806 en el Journal de Physique.

\section{La completa ausencia de referencias a Proust en los estudios $y$ análisis de los carbones asturianos del siglo XIX}

La notable difusión que tuvieron los análisis de los carbones realizados por Proust en el continente europeo contrasta vivamente con la ausencia de cualquier tipo de mención, cita o referencia por parte de los científicos, técnicos e ingenieros que estudiaron y dieron a conocer las cuencas mineras asturianas entre los inicios de los años treinta y finales de los cincuenta del siglo XIX. Algo que resulta chocante, pues la mayoría de ellos no eran españoles y se habían formado en el extranjero.

La primera de estas ausencias se puede constatar en el informe sobre las minas de carbón de piedra de la provincia de Asturias publicado en 1831 por Joaquín Ezquerra (1793-1859), Felipe Bauzá (1802-1875), Rafael Amar (1802-1874) y Francisco García (?-?), quienes, sin embargo, refieren la existencia en las proximidades del puerto de Pajares de una antracita muy negra que los naturales utilizaban para hacer tinta, de la que ya había dado cuenta Proust (Ezquerra et al., 1831; Álvarez y Fernández, 2018). Nueve años después, el ingeniero de minas francés Armand Buvignier (18081880) tampoco hizo ninguna alusión a los ensayos de su compatriota en su artículo Note géologique sur les Asturies (Buvignier, 1839; Álvarez y Fernández, 2018).

Más sorprendente es el desconocimiento de la obra de Proust que evidencian el químico inglés John Thomas Cooper y el ingeniero francés Adrien Paillette, pues fueron quienes Ilevaron a cabo nuevos análisis de los carbones asturianos a comienzos de la década de los años cuarenta del siglo XIX, momento en que se intentó volver a potenciar la creación de industrias siderúrgicas en la región, una vez superada la primera guerra carlista.

Cooper se encargó de ensayar los carbones del distrito deTudela para un grupo de inversores británicos, que tenía la intención de constituir una gran empresa denominada The Asturian Coal and Iron Company. Para ello destiló el carbón de tres minas, obteniendo entre un 66 y un $68 \%$ de coque, lo que le llevaría a ensalzar su excelente calidad y la idoneidad para la obtención de vapor, el forjado, la obtención de gas y los usos domésticos (Cooper, 1842; Álvarez y Fernández, 2018).

Por su parte, Paillette llegó a Asturias a principios de los años cuarenta para dirigir las explotaciones de carbón de Ferroñes (Llanera) y abordó por su cuenta la tarea de ensayar químicamente un gran número de hullas de la región, presentando en 1843 los resultados obtenidos a la Sociedad Económica de Asturias. Fruto de ello fue una pequeña memoria en 
la que decía que hasta aquel momento faltaban por conocer metódicamente los principios elementales de los carbones de piedra asturianos y presentarlos de manera que los capitalistas e industriales pudieran ver sus posibles aplicaciones, comparándolos con otros conocidos de Francia, Bélgica e Inglaterra. A diferencia de Proust, hizo una descripción pormenorizada de la consistencia, color y grado de compactación de las hullas utilizadas y describió las características de los tipos de coque obtenidos, reseñando su color, solidez, aspecto y consistencia (Paillette, 1843).

No es posible realizar una comparación directa entre los resultados de Proust y de Paillette, ya que éste no ensayó los carbones de Quirós y Riosa, ni tampoco las capas de hullas analizadas por ambos fueron las mismas. Esto último podría justificar, en parte, el hecho de que mientras Proust obtuvo de los carbones de Langreo cantidades de coque comprendidas entre el $64 \%$, de la mina del Fondón, y el $76 \%$, de la de Rionda, fijando un $75 \%$ para el que denominaba genéricamente como de Langreo, Paillette consiguió entre el $54,6 \%$, correspondiente a la capa de EI Serradero, y el $61 \%$, de las minas Carbonero y Colasa. Sin embargo, en el caso de los carbones de Lieres existe una gran coincidencia en los resultados, ya que Proust refirió un $60 \%$ de coque, mientas que Paillette un $59,6 \%$. Asimismo, ambos están de acuerdo en la presencia de gran cantidad de piritas en las muestras analizadas.

Esta primera memoria de Paillette referida a los análisis químicos de los carbones asturianos volvió a ser publicada en Madrid hacia 1845 o 1846, como parte integrante del folleto para la suscripción de las acciones del futuro Ferrocarril Minero de Langreo, y de nuevo en 1849 en París, traducida al francés, coincidiendo con el momento en el que grandes capitalistas nacionales y extranjeros especulaban con la potencialidad minero-siderúrgica de la región.

De hecho, entre 1848 y 1850 Paillette volvió a realizar nuevos análisis de los carbones asturianos, centrándose en esta ocasión, sobre todo, en las minas que él mismo dirigía: las de Carbayín (Siero), propiedad del duque de Riánsares; las que posteriormente se agruparían en el Coto de Mosquitera (Langreo), propiedad de Adolphe d'Eichthal; las de Mieres, propiedad de Lillo y Cía; las de Lena, propiedad de la Compañía Lenense Asturiana, así como algunas situadas en Olloniego (actual concejo de Oviedo). Del total de 43 minas analizadas, la mayor cantidad de coque $(78 \%)$ la obtuvo de la denominada La Fabiana, sita en Carabanzo (Lena), y la que ofreció menor proporción (53\%) fue la titulada Las Llamargas, en Carbayín, mientras que un lignito de Aragón, remitido para hacer su comparación, ofreció un $56,25 \%$ y el "carbón empleado en Valladolid" un 75,35\%.
En esta memoria, el ingeniero francés insiste en la dificultad que ofrecía la deducción de las consecuencias del análisis químico de los productos, ya fuera para establecer su valor industrial, o para buscar analogías, por medio de su composición, que permitieran comparar varias capas o reunirlas por grupos determinados. En este sentido, para afinar más sus resultados aplicó un método empírico con el que determinar la cantidad de azufre que retenían los coques en determinadas circunstancias y concluyó sus observaciones señalando los malos efectos que había producido en el comercio de los carbones asturianos el que se compraran sin conocimiento alguno de su composición (Paillette, 1855; Álvarez y Fernández, 2018).

Simultáneamente, el capitán de Artillería Manuel de Azpiroz (1828-1892) también llevó a cabo el análisis de gran cantidad de carbones, procedentes de los principales criaderos de la región, en el laboratorio de química de la Fábrica de Trubia, restablecida con éxito en 1844 por el general Francisco Antonio de Elorza (1798-1873). En el folleto que publicó en 1857 para dar a conocer los resultados obtenidos, indicaba que eran una continuación de los realizados por Paillette a comienzos de los años cuarenta, olvidando igualmente, aunque de forma más incomprensible aún, el precedente sentado por Proust. Además de los ensayos habituales para determinar la proporción de coque y de cenizas de cada una de las muestras, estableció su poder calorífico aplicando el método desarrollado por el catedrático de docimasia de la École des Mines de París, Pierre Berthier (1782-1861), y cuantificó el contenido de azufre por un procedimiento más elaborado que el de Paillette.

En sus conclusiones, afirmaba que en Asturias se podían encontrar todas las variedades de carbón de piedra conocidas. La cantidad de coque que podían producir oscilaba entre un $54 \%$ y un $64 \%$, valores muy inferiores a los establecidos en su momento por Proust, y la proporción de cenizas desde el 2 o $3 \%$ de los más limpios, hasta el 8 o 10\% de los más impuros. Consideraba que todos los carbones de Sama, Siero, Santa Ana y Riosa eran apropiados para hacer coque y para los usos industriales (Azpiroz, 1857; Álvarez y Fernández, 2018).

Por su parte, el ingeniero de minas Guillermo Schulz (1805-1877), que fue quien mejor estudió la geología de la región en aquella época, tampoco hizo ninguna mención en sus escritos a los análisis químicos realizados por Proust. En su obra magna-Descripción geológica de la provincia de Oviedo (1858)- señala que la calidad de las hullas variaba, incluso, de unos bancos a otros dentro de un mismo grupo, y que los ensayos docimásticos hechos por Paillette y Azpiroz habían demostrado la necesidad de distinguir los di- 
ferentes carbones y no mezclarlos ciegamente en un mismo cargamento o para un mismo destino. Guardando esas precauciones en la explotación y el comercio, consideraba que, por lo menos, sesenta bancos del centro de Asturias ofrecían un combustible excelente para todos los usos metalúrgicos.

A partir de entonces, la omisión a la labor analítica desempeñada por Proust se fue generalizando en todos los trabajos que irían apareciendo sobre la historia de los carbones asturianos. Tan solo el tenaz investigador Luis Adaro Ruiz-Falcó reparó en el trabajo desarrollado por el prestigioso químico francés, aunque lamentaría profundamente no haber podido localizar los resultados de sus ensayos (Adaro, 1981).

\section{Conclusiones}

Los análisis químicos de los carbones minerales llevados a cabo por Joseph Louis Proust en el laboratorio del Real Colegio de Artillería de Segovia a finales del siglo XVIII, constituyen un interesante ejemplo de aplicación del conocimiento científico de la época al intento de resolución de un problema industrial. EI hecho de que se realizaran en un momento en el que el proceso de fundición del hierro en hornos altos alimentados con coque presentaba aún serias incógnitas, explica que la memoria en la que el científico francés expuso sus resultados consiguiera una amplia difusión en Europa. A pesar de ello, en España pasó completamente desapercibida y pronto quedó relegada en el olvido.

El impacto que la Guerra de la Independencia y la posterior reacción absolutista de Fernando VII tuvieron en el incipiente despertar científico español, debió contribuir decisivamente a ello. Tampoco ayudó que los ensayos de Proust no lograran solventar la cuestión para la que fue consultado, aunque, tal y como acertadamente señaló en su momento Jovellanos, cabe atribuir el fracaso del primer intento de puesta en marcha de la Fábrica de Trubia a una multiplicidad de causas que derivarían, fundamentalmente, de la improvisación y la falta de preparación técnica de los encargados del establecimiento y de sus operarios.

Sin embargo, se debe tener en cuenta que en 1804 el presbítero, naturalista e industrial José Vicente $\mathrm{Pe}$ reda (1760-1820) redactó una Memoria sobre el carbón fósil por encargo de la Junta General del Principado de Asturias, en la que señalaba que Dátoli "trabajó con algún esmero para facilitar las fundiciones del hierro por el intermedio de este combustible (coque); hubiera podido hacer algún adelantamiento habiéndose acostumbrado más a manejar esta materia, y permaneciendo en su comisión. Proust no solo no adelantó nada en su reconocimiento, sino que desmayó al Gobierno obligándole a una resolución, cuyos resultados han sido el abandono del beneficio de las minas de este fósil y la ruina de la provincia en este interesante ramo" (Pereda, 1814; Álvarez y Fernández, 2018).

De sus palabras parece desprenderse que la R.O. del 01 de octubre de 1803, por la que se dispuso el cierre de las empresas de navegación del río Nalón y de explotación de las minas de Langreo, sostenidas por la Marina, habría sido una consecuencia directa de la opinión de Proust de que no sería posible conseguir los combustibles que se necesitarían a diario para alimentar los altos hornos de Trubia. Este parecer se lo habría transmitido en fecha no determinada al gobierno y lo reprodujo posteriormente en sus Faits pour servir à l'Histoire des charbons de terre (Proust, 1806a). Tal y como se ha expuesto anteriormente, su estimación se sustentaba en el poco espesor que, en general, presentaban las vetas de carbón asturiano $y$, sobre todo, en su alto contenido en pirita, que difícilmente se podría eliminar mediante el proceso de carbonización. De esta forma, sus análisis químicos de los carbones habrían tenido una repercusión trascendental en la historia minero-industrial de Asturias.

En todo caso, también hay que considerar que el plan de abandono de las citadas empresas, suscrito en 1803 por el capitán de fragata Juan Bautista de Aguirre (?-?), se basaba en la destrucción de las obras de canalización del río Nalón por una devastadora riada y en los excesivos costes de las explotaciones mineras, sin que en ningún momento se aludiera a la calidad de los carbones extraídos. Asimismo, tanto el comandante de La Cavada, Pedro Varela (1737-1797), como el brigadier de la Armada, Cayetano Valdés (1767-1834), se mostraron partidarios de mantener las minas con otra organización, si bien sería para continuar abasteciendo los arsenales con carbón mineral asturiano (Adaro, 1981).

Sea como fuera, la cuestión es que a pesar de los esfuerzos desarrollados por el Estado para reconvertir el proceso de fundición tradicional a otro basado en el carbón mineral, no fue posible solventar las dificultades técnicas surgidas en el empeño, frustrándose así el cambio de paradigma energético que debería haber abierto el paso a la industrialización (Nadal, 1975). Y en este fracaso influyó, sin ninguna duda, la falta de experiencia en la preparación y manejo del coque, ya que la selección adecuada de las hullas que han de componer la mezcla a destilar en el proceso de coquización condiciona en un $70-80 \%$ la calidad del coque (Díez, 2013), para lo cual resulta esencial, aún en la actualidad, determinar la capacidad coquizante de las mismas mediante análisis químicos (contenido de ce- 
nizas, azufre, compuestos alcalinos, materias volátiles y humedad) y otros ensayos de laboratorio. Así y todo, este es un aspecto que, al igual que los análisis químicos de los carbones minerales realizados por Proust, no ha sido contemplado por la historiografía minero-industrial de Asturias y bien merece un estudio en profundidad.

\section{Referencias}

Adaro Ruiz-Falco, L. 1981. Datos y documentos para una historia minera e industrial de Asturias, I. Suministros Adaro, Gijón, 750 pp.

Adaro Ruiz-Falco, L. 1986. Los comienzos de las fábricas de municiones gruesas de Trubia y de armas de Oviedo (1792-1799). Boletín del Instituto de Estudios Asturianos, XL (118), 339-451.

Alcalá-Zamora, A. 1974. Historia de una empresa siderúrgica española: los altos hornos de Lierganes y La Cavada, 1622-1834. Diputación Provincial de Santander, Institución Cultural de Cantabria (CSIC) y Centro de Estudios Montañeses, Guarnizo, 267 pp.

Álvarez Muñoz, E. y Fernández Sampedro, L. 2018. Biblioteca Geológica y Minera de Asturias hasta 1900. Colegio Oficial de Ingenieros de Minas del Noroeste, Escuela de Ingeniería de Minas, Energía y Materiales de Oviedo, Universidad de Oviedo, 107 pp.

Azpiroz, M. 1857. Análisis de varios carbones de Asturias hecho en el laboratorio de química de la Fábrica de Trubia. Imp. y Lit. de D. Benito González, Oviedo, 28 pp.

Baig i Aleu, M. 2010. Del laboratorio a la industria: Louis Joseph Proust a la Reial Foneria de Sant Sebastià de la Muga. Actes d'Història de la Ciència i de la Técnica, Nova Época, 3 (1), 23-36.

Bonet, M. 1885 y 1886. Los laboratorios de Mr. Proust. Apéndice al discurso del Dr. Bonet leído en la inauguración del presente curso académico en la Universidad Central. La Farmacia Española, 48, 49, 50, 51.

Bonnard, A.H. 1805. Mémoire sur les procédés employés en Angleterre pour le traitement du fer par le moyen de la houille. Journal de Mines, XVII (100), 7.

Brongniart, A. 1807. Traité Élémentaire de Minéralogie, avec des applications aux arts, II, París, 446 pp.

Bussy, A. 1826. Notice nécrologique sur Joseph-Louis Proust, membre de I'Institut et de la Légion d'Honneur, pharmacien, membre de l'Académie Royale de Médecine. Journal de Pharmacie et des Sciencies Accesoires, XII, 379-387.

Buvignier, A. 1839. Note géologique sur les Asturies. Bulletin de la Société Géologique de France, X, 100-104.

Cooper, J.T. 1842. Report by Mr. John Thomas Cooper, Lecturer on Chemistry, and Chemical Assayest. In: Forster, M., Cooper, J.T. and Jamieson, A. Report on the coal mi- nes and iron ores in the district of Tudela, in the Asturias in Spain, Newcastle, 40 pp.

David, H. 1938. Une correspondance inédite du grand chimiste Joseph-Louis Proust, apothicaire éclairant sa biographie (1754-1826). Revue d'Histoire de la Pharmacie, 101, 266-279.

Delamétherie, J.C. 1807. Discurso Préliminaire. Journal de Physique, de Chimie, d'Histoire Naturelle et de Arts, LXIV, 5-115.

Delamétherie, J.C. 1814. Suite a mes mémoires sur les cristallisations géologiques. De la formation des houilles et des substances bitumineuses. Journal de Physique, de Chimie, d'Histoire Naturelle et des Arts, LXXVIII, 241-269.

Díez, M.A. 2013. Del carbón vegetal al coque en la industria del hierro y del acero. Fundipress: revista de la fundición, 45, 48-56.

Esteva de Sagrera, J. y Espinosa Ramos, E. 1990. El proceso de Proust por la Inquisición española. Publicaciones de la Cátedra de Historia de la Farmacia, V, 69-82.

Ezquerra del Bayo, J., Amar de laTorre, R., Bauzá, F. y García, F. 1831. Minas de carbón de piedra en Asturias. Imprenta de Don José del Collado, Madrid, 62 pp., 4 lám., 1 mapa.

Fabbroni, G. 1790. Dell'antracite o carbone di cava detto volgarmente carbon fossile. Gaetano Cambiagi, Stampa Imperiale, Florencia, 359 pp.

Fagés y Virgili, J. 1909. Los químicos de Vergara y su obra. Discurso de recepción ante la Real Academia de Ciencias Exactas, Físicas y Naturales. Est. Imprenta y Editorial Pontejos $\mathrm{n}^{\circ}$ 8. Madrid.

Fernández de Castro, M. 1874. Para un estudio bibliográfico sobre los orígenes y estado actual del mapa geológico de España. Boletín de la Comisión del Mapa Geológico de España, I, 17-168.

Florián Reyes, M.L. 1999. La obra de Louis Proust: traducción y creación de la lengua de la química. In Lafarga, F. (coord.): La traducción en España (1750-1830): lengua, literatura, cultura. Universidad de Lleida, 131-142.

Fournier, J. 1999. Louis-Joseph Proust (1754-1826) était-il pharmacien? Revue d'Histoire de la Pharmacie, 321, 7796.

Fournier, J. 2012. Deux contributions majeurs à la définition de I'Espèce chimique: Proust et Chevreul. Bulletin de la Sabix. Société des amis de la bibliothèque et de I'histoire de l'École polytechnique, 50, 45-59.

Fraga Vázquez, X.A. 1995. El plan de la Real Escuela Práctica de Química de Madrid (1803), una alternativa institucional para la incorporación de la química en el Estado Español. Llull: Revista de la Sociedad Española de Historia de las Ciencias y de las Técnicas, 18 (35-36), 35-65.

Fujii, K. 1986. The Berthollet-Proust controversy and Dalton's chemical atomic theory. British Journal of History of Science, 19, 177-200.

Gago Bohorquez, R. 1978. Bicentenario de fundación de la cátedra de Química de Vergara. El proceso de constitu- 
ción. Llull: Revista de la Sociedad Española de Historia de las Ciencias y de las Técnicas, 2, 10.

Gago Bohorquez, R. 1988a. The New Chemistry in Spain: Essays in Reinterpretation. Osiris, 4, 169-192.

Gago Bohorquez, R. 1988b. Cultivo y enseñanza de la química en la España de principios del siglo XIX. In: Sánchez Ron, J. M. (ed.), Ciencia y sociedad en España. Ediciones EI Arquero/CSIC, Madrid, 129-142.

Gago Bohorquez, R. 1992. Louis Proust y el laboratorio del Real Colegio de Artillería de Segovia. In: La casa de la Química, ciencia, artillería e ilustración, catálogo de la exposición celebrada en Segovia en conmemoración del Bicentenario de la Casa de la Química, Madrid, Ministerio de Defensa, Secretaría General Técnica, 73-84.

Gago Bohórquez, R. y Mauskopf, S. H. 1984. Represión ideológica, inquisición y ciencia en la España de la segunda mitad del siglo XVIII: el caso de los físicos Agustín La Planche y Luis José Proust. In: Hormigón Blánquez, M. (coord.), Actas del II Congreso de la Sociedad Española de Historia de las Ciencias, 3, 94.

García Belmar, A. y Bertomeu Sánchez, J.R. 2003. Constructing the centre from the periphery. Spanish Travellers to France at the time of the Chemical Revolution. In: Simoes, A., Carneiro, A. and Diogo, M.P. (eds.), Travels of Learning. A Geography of Science in Europe. Kluwer Academic Publishers, 143-188.

Gazeran, I. 1790. Memoire sur les fers de fonte obtenus avec le charbon de terre dessoufré ou réduit en coak, \& sur la ténacité comparée avec celle des fontes qui proviennent des forges oú l'on n'emploie que le charbon de bois. Annales de Chimie ou Recueil de mémoires concernant la Chimie et les Arts qui en dépendent, VII, 97-112.

Gazeran, I. 1800. Observations sur le traitement des mines de fer avec la houille carbonisée, connue sous le nom de coak. Annales de Chimie, XXXI, 113-121.

Godard-Faultrier, V. 1852. Notice biographique sur le chimiste J.-L. Proust. Bulletin Société Industrielle et $\mathrm{Co}$ merciale d'Angers et du Département de Maine \& Loire, XXIIIle année, $3^{\mathrm{e}}$ de la $2^{\mathrm{e}}$ série (23), 17-45.

González de Azaola, G. 1825. Informe sobre la fundición de hierro con hornaguera. In: Alcalá-Zamora, A. 1974. Historia de una empresa siderúrgica española: los altos hornos de Lierganes y La Cavada, 1622-1834. Diputación Provincial de Santander, Institución Cultural de Cantabria (CSIC) y Centro de Estudios Montañeses, Guarnizo, 267 pp.

Herrero y Fernández-Quesada, M. D. 1993. Cañones y probetas en el Alcázar. Un siglo de la historia del Real Colegio de Artillería de Segovia (1764-1862). Patronato del Alcázar de Segovia. Segovia, 76 pp.

Huici, V. 1931. Miscelánea de trabajos inéditos varios y dispersos de D.G.M. Jovellanos, dispuestos para la impresión por Vicente Huici Miranda. Nagsa, Barcelona, $311 \mathrm{pp}$.

Jars, A.G. 1774. Voyages métallurgiques ou Recherches et observations sur les mines, I, 325-338.
Jovellanos, G. M. de. 1797. Informe reservado sobre el Real establecimiento de La Cavada. In: Jovellanos, G. M. de (2006), Obras Completas, X (Escritos económicos). KRK, Oviedo, 252-253.

Kirwan, R. 1796. Of the composition and proportion of carbon in bitumens and mineral coal. Dublín, $29 \mathrm{pp}$.

Koper, S. C. 1965. Berthollet, Proust and Proportions. Chymia, 10, 53-110.

Larruga, E. 1793. Memorias políticas y económicas sobre los frutos, comercio, fábricas y minas de España, XXV. Madrid, $304 \mathrm{pp}$.

Marcelo Rodao, G. 2011. La construcción de la "Casa de la Química" (1787-1790): un laboratorio científico militar en la Segovia del siglo XVIII. Espacio, Tiempo y Forma, Serie IV, Historia Moderna, 24, 189-202.

Mauskopf, S. H. 1975. Proust, Joseph Louis. In: Guillespie C.C. (ed.), Dictionary of scientific biography, New York, Charles Scribner's Sons, 11, 166-172.

Mauskopf, S. H. 1990. Chemistry and Cannon: J.-L. Proust and Gunpowder Analysis. Technology and Culture, 31, 398-426.

Morand, J.F.C. 1776. L'art d'exploiter les mines de charbon de terre, II, 1117.

Nadal, J. 1975. El fracaso de la Revolución Industrial en España, 1814-1913. Ariel, Barcelona, 320 pp.

Paillette, A. 1843. Ensayos químicos de algunos carbones de Asturias, presentadas a su Sociedad económica por su socio de mérito. Imprenta de D. Benito González y Compañía, Oviedo, 12 pp.

Paillette, A. 1855. Ensayos de carbones asturianos, acompañados de algunas reflexiones sobre los productos de incineración. Revista Minera, VI, 66-69.

Pereda, J.V. 1814. Memoria sobre e carbón fósil: presentada en virtud de encargo, á la Junta General Extraordinaria del Principado de Asturias celebrada con aprobación de S.M. en 1804. Oviedo, Oficina de Prieto, 12 pp.

Peret, J. L.; Garma, S. y Pérez Garrón, J. S. 1978. Ciencias y enseñanza en la revolución burguesa. Siglo XXI, Madrid, $244 \mathrm{pp}$.

Portela Marco, E. 1983. Proust, Luis José. In: López Piñeiro, J. M. et al. (eds.), Diccionario histórico de la ciencia moderna en España, 2, 201-205.

Proust, L.J. 1792. Discurso que en la abertura del Laboratorio de Chimia del expresado Real Colegio de Artillería, establecido en Segovia pronunció Don Luis Proust, profesor de Chimia del expresado Real Cuerpo. Segovia, Imp. de Espinosa. 50 pp.

Proust, L.J. 1799. Sur la proportion du charbon dans quelques bois, et sur celle des charbons de terre. Journal de Physique, Chimie, d'Histoire Naturelle et des Arts, XLVIII, 469-471. 
Proust, L.J. 1806a. Faits pour servir à I'Histoire des charbons de terre. Journal de Physique, de Chimie, d'Histoire Naturelle, et des Arts, LXIII, 320-338.

Proust, L.J. 1806b. Fonte de Fer. Journal de Physique, de Chimie, d'Histoire Naturelle, et des Arts, LXIII, 463-467.

Proust, L.J. 1810. Faits pour servir a l'étude de la poudre a canon. Journal de Physique, de Chimie, d' Histoire Naturelle et des Arts, LXX, 320-340.

Puerto Sarmiento, J. 1994. La huella de Proust: El laboratorio de química del Museo de Historia Natural. Asclepio, Revista de Historia de la Medicina y de la Ciencia, XLVI (1), 197-220.
Rodríguez Carracido, J. 1897. Don Louis Proust en España. In: Estudios histórico-críticos de la ciencia española, 233-247.

Schulz, G. 1858. Descripción geológica de la provincia de Oviedo. Imprenta y librería de D. José González, Madrid, 138 pp.

Silván, L. 1953. Los estudios científicos en Vergara a fines del siglo XVIII: el químico Luis José Proust 1754-1826. Real Sociedad Bascongada de Amigos del País. 319 pp.

Suárez Menéndez, R. 1993. Fábrica de Trubia. 1794-1987. Historia y producción artística. Centro de escultura de Candás, Museo Antón, Carreño, 235 pp.

Wisniak, J. 2012. Joseph Louis Proust. Revista CENIC Ciencias Químicas, 43, 126-144.

Recibido: julio 2019

Revisado: noviembre 2019

Aceptado: enero 2020

Publicado: marzo 2021 